FUNCTION SPACES X

BANACH CENTER PUBLICATIONS, VOLUME 102

INSTITUTE OF MATHEMATICS

POLISH ACADEMY OF SCIENCES

WARSZAWA 2014

\title{
STRUCTURE OF CESÀRO FUNCTION SPACES: A SURVEY
}

\author{
SERGEY V. ASTASHKIN ${ }^{\dagger}$ \\ Department of Mathematics and Mechanics, Samara State University \\ Acad. Pavlova 1, 443011 Samara, Russia \\ E-mail: astash@samsu.ru \\ LECH MALIGRANDA \\ Department of Mathematics, Lulea University of Technology \\ SE-971 87 Luleå, Sweden \\ E-mail: lech.maligranda@ltu.se
}

\begin{abstract}
Geometric structure of Cesàro function spaces $\operatorname{Ces}_{p}(I)$, where $I=[0,1]$ and $[0, \infty)$, is investigated. Among other matters we present a description of their dual spaces, characterize the sets of all $q \in[1, \infty]$ such that $C e s_{p}[0,1]$ contains isomorphic and complemented copies of $l_{q}$-spaces, show that Cesàro function spaces fail the fixed point property, give a description of subspaces generated by Rademacher functions in spaces $C e s_{p}[0,1]$.
\end{abstract}

1. Introduction. Many Banach spaces which play an important role in functional analysis and its applications are obtained in a special way: the norms of these spaces are generated by positive sublinear operators and by $L_{p}$-norms. The well-known examples of such spaces are real interpolation and extrapolation spaces, Besov spaces $B_{p, q}^{s}$, Triebel spaces $F_{p, q}^{s}$, "tent" spaces and many others. One of the simplest and, at the same time, most important examples are Cesàro sequence and function spaces.

2010 Mathematics Subject Classification: 46E30, 46B20, 46B42.

Key words and phrases: Cesàro sequence and function spaces, Copson sequence and function spaces, Köthe dual, associated space, dual space, copies of $l_{p}$, Dunford-Pettis property, RadonNikodym property, weak Banach-Saks property, Rademacher functions, type and cotype, isomorphism, subspaces, complemented subspaces, fixed point property, interpolation, K-functional, K-method of interpolation.

${ }^{\dagger}$ Research partially supported by RFBR grant no. 12-01-00198-a.

The paper is in final form and no version of it will be published elsewhere. 
The Cesàro sequence spaces are known much better than the function ones. The spaces ces $_{p}$ are defined as the sets of all real sequences $x=\left\{x_{k}\right\}$ such that

$$
\|x\|_{c(p)}=\left[\sum_{n=1}^{\infty}\left(\frac{1}{n} \sum_{k=1}^{n}\left|x_{k}\right|\right)^{p}\right]^{1 / p}<\infty, \quad \text { when } 1 \leq p<\infty,
$$

and

$$
\|x\|_{c(\infty)}=\sup _{n \in \mathbf{N}} \frac{1}{n} \sum_{k=1}^{n}\left|x_{k}\right|<\infty, \quad \text { when } \quad p=\infty .
$$

The Cesàro sequence spaces appeared explicitly in 1968 when the Dutch Mathematical Society posted the problem to find a representation of their duals. For the first time some investigations of $c e s_{p}$ were done by Shiue [80] in 1970. Then Leibowitz [57] and Jagers [44] proved that $c e s_{p}$ are separable reflexive Banach spaces for $1<p<\infty$, ces $_{1}=\{0\}$ and that $l_{p}$-spaces are strictly and continuously embedded into ces $_{p}$ for $1<p \leq \infty$. More precisely, $\|x\|_{c(p)} \leq p^{\prime}\|x\|_{p}$ for all $x \in l_{p}$, with $p^{\prime}=\frac{p}{p-1}$ when $1<p<\infty$ and $p^{\prime}=1$ when $p=\infty$. Moreover, if $1<p<q \leq \infty$, then ces $_{p} \subset c e s_{q}$, and this embedding is continuous and strict. Bennett [17] proved that $\operatorname{ces}_{p}$ for $1<p<\infty$ is not isomorphic to any $l_{q}$-space with $1 \leq q \leq \infty$ (see also [69] for another proof).

Various geometric properties of the Cesàro sequence spaces ces $s_{p}$ were studied in the last years by many mathematicians (see e.g. [24], [26], [27], [28], [29], [30], [31], [55]). In particular, in 2007 Maligranda-Petrot-Suantai [69] proved that ces $_{p}$ for $1<p<\infty$ are not uniformly non-square, that is, there are sequences $\left\{x_{n}\right\}$ and $\left\{y_{n}\right\}$ from $c e s_{p}$ such that $\left\|x_{n}\right\|_{c(p)}=\left\|y_{n}\right\|_{c(p)}=1$ and $\lim _{n \rightarrow \infty} \min \left(\left\|x_{n}+y_{n}\right\|_{c(p)},\left\|x_{n}-y_{n}\right\|_{c(p)}\right)=2$. Moreover, they proved that these spaces have trivial Rademacher type. Some more results on $c_{p} s_{p}$ can be found in two books [17, 62.

The main goal of this survey is to give a comprehensive exposition of recent results on the structure of Cesàro function spaces which for a long time have not attracted a lot of attention in contrast to their sequence counterparts. The Cesàro function spaces $C e s_{p}=C e s_{p}(I), 1 \leq p \leq \infty$, are classes of all Lebesgue measurable real functions $f$ on $I=[0,1]$ or $I=[0, \infty)$ such that

$$
\|f\|_{C(p)}=\left[\int_{I}\left(\frac{1}{x} \int_{0}^{x}|f(t)| d t\right)^{p} d x\right]^{1 / p}<\infty \quad \text { for } \quad 1 \leq p<\infty,
$$

and

$$
\|f\|_{C(\infty)}=\sup _{x \in I, x>0} \frac{1}{x} \int_{0}^{x}|f(t)| d t<\infty \text { for } p=\infty .
$$

The space $\mathrm{Ces}_{\infty}[0,1]$ appeared already in 1948 and it is known as the KorenblyumKrein-Levin space $K$ (see [52], [91, p. 26, 61] and [92, pp. 469-471]). The Cesàro function spaces $\operatorname{Ces}_{p}[0, \infty)$ for $1 \leq p \leq \infty$ were considered for the first time in 1970 by Shiue [81], later these spaces were studied by Hassard-Hussein [42] and Sy-Zhang-Lee [85].

Recently, the structure and geometry of Cesàro function spaces were investigated by Astashkin-Maligranda in several papers [7, 8, 9, 10, 11, 12, 13] and by others [5], 46].

This survey paper is organized as follows. In Section 2 some necessary definitions and notations are collected. In Section 3 we consider the simplest properties of Cesàro 
function spaces. In particular, they are not reflexive but strictly convex for all $1<p<\infty$. Moreover, we discuss here a number of embeddings between Cesàro function spaces, $L_{p}$-spaces and the so-called Copson spaces.

Section 4 contains results on the dual and Köthe dual of Cesàro function spaces. Recall that Luxemburg-Zaanen 65] gave a description of the Köthe dual $\left(\mathrm{Ces}_{\infty}[0,1]\right)^{\prime}$. In Theorems 4.1 and 4.6 we present an isomorphic representation of the dual space $\left(\operatorname{Ces}_{p}(I)\right)^{\prime}, 1<p<\infty$. These results show an essential difference between the cases $[0, \infty)$ and $[0,1]$. The description on $[0, \infty)$ is in a sense similar to the one given for sequence spaces by Bennett [17] (see also there his remark on the Köthe dual $\left.\left(\operatorname{Ces}_{p}[0, \infty)\right)^{\prime}\right)$.

In Section 5, it is proved that the Cesàro function space $\operatorname{Ces}_{p}(I), 1<p \leq \infty$, contains an order isomorphic and complemented copy of the $l_{p}$-space (see Theorem 5.1(c)). Therefore, $\operatorname{Ces}_{p}(I), 1<p<\infty$, does not have the Dunford-Pettis property. This result combined with some other known results implies that, for every $1<p \leq \infty, \mathrm{Ces}_{p}(I)$ is not isomorphic to any $L_{q}(I)$ space for $1 \leq q \leq \infty$ (see Theorem 5.4). Moreover, we present here a description of isomorphic and complemented copies of $l_{q}$-spaces in $C e s_{p}[0,1]$. In particular, for every $1<p \leq \infty$ the space $\operatorname{Ces}_{p}(I)$ contains an asymptotically isometric copy of $l_{1}$. Therefore, Cesàro function spaces are not reflexive and do not have the fixed point property, in contrast to Cesàro sequence spaces $c e s_{p}$, which for $1<p<\infty$ are reflexive and do have the fixed point property.

Section 6 deals with the $p$-concavity, Rademacher type and cotype of Cesàro function spaces. In particular, in Theorem 6.1 it is shown that $\operatorname{Ces}_{p}(I)$ is $p$-concave for $1<p<\infty$ with constant one and, thus, it has cotype $\max (p, 2)$.

In Section 7 we give a construction of operators showing that the Cesàro spaces $\operatorname{Ces}_{p}[0, \infty)$ and $\operatorname{Ces}_{p}[0,1]$ are isomorphic if $1<p \leq \infty$. The question if $\operatorname{Ces}_{\infty}[0,1]$ is isomorphic to $\mathrm{ces}_{\infty}$ is still an open problem.

Section 8 contains results on subspaces spanned by the Rademacher functions in $\operatorname{Ces}_{p}[0,1], 1 \leq p \leq \infty$. We show that these functions span in $\operatorname{Ces}_{p}[0,1], 1 \leq p<\infty$, an uncomplemented subspace isomorphic to $l_{2}$. We give also a description of the subspace spanned by the Rademacher functions in $\mathrm{Ces}_{\infty}[0,1]$. This uncomplemented subspace has many interesting properties. In particular, the standard unit vectors form in it a conditional basis.

In Section 9 we present Theorem 9.1 showing that for $1 \leq p<\infty$ the Cesàro function spaces $\operatorname{Ces}_{p}[0,1]$ have the weak Banach-Saks property. The proof of the latter result is based on the description of the dual space given in Section 4 and on a result characterizing weakly null sequences in $\mathrm{Ces}_{p}[0,1], 1<p<\infty$.

Finally, Section 10 contains interpolation results for Cesàro and Copson spaces. It is shown that the Cesàro function space $\operatorname{Ces}_{p}(I)$, where $I=[0,1]$ or $[0, \infty)$, is an interpolation space between $C e s_{p_{0}}(I)$ and $C e s_{p_{1}}(I)$ for $1<p_{0}<p_{1} \leq \infty$ and $1 / p=(1-\theta) / p_{0}+$ $\theta / p_{1}$ with $0<\theta<1$. The same result is true for Cesàro sequence spaces. In the case of Copson function and sequence spaces a similar result holds even if $1 \leq p_{0}<p_{1} \leq \infty$. At the same time, $\operatorname{Ces}_{p}[0,1]$ is not an interpolation space between $\operatorname{Ces}_{1}[0,1]$ and $C e s_{\infty}[0,1]$ for any $1<p<\infty$. Moreover, we give a description of interpolation spaces which are obtained from the Banach couple $\left(\operatorname{Ces}_{1}[0,1], \mathrm{Ces}_{\infty}[0,1]\right)$ by the real method of interpolation. 
2. Preliminaries and notation. We recall first some notions and definitions which we will need later on. For two normed spaces $X$ and $Y$ the symbol $X \stackrel{C}{\hookrightarrow} Y$ means that the embedding $X \subset Y$ is continuous with the norm which is not greater than $C$, i.e., $\|x\|_{Y} \leq C\|x\|_{X}$ for all $x \in X$, and $X \hookrightarrow Y$ means that $X \stackrel{C}{\hookrightarrow} Y$ for some $C>0$. Moreover, we write $X=Y$ if $X \hookrightarrow Y$ and $Y \hookrightarrow X$, that is, the spaces are the same and the norms are equivalent. At the same time, notation $X \simeq Y$ is used if these two spaces are isomorphic. If $f$ and $g$ are nonnegative functions, then the symbol $f \approx g$ means that $c^{-1} g \leq f \leq c g$ for some $c \geq 1$.

By $L_{0}=L_{0}(I)$ we denote the set of all equivalence classes of real-valued Lebesgue measurable functions defined on $I=[0,1]$ or $I=[0, \infty)$. A normed function lattice or normed ideal space $X=(X,\|\cdot\|)$ (on $I$ ) is understood to be a normed space $X \subset L_{0}(I)$, which satisfies the so-called ideal property: if $|f| \leq|g|$ a.e. on $I, f \in L_{0}$ and $g \in X$, then $f \in X$ and $\|f\| \leq\|g\|$. If, in addition, $X$ is a complete space, then we say that $X$ is a Banach function lattice or a Banach ideal space (on $I$ ). Sometimes we write $\|\cdot\|_{X}$ to be sure in which space the norm is taken.

For a normed ideal space $X=(X,\|\cdot\|)$ on $I$ and $1<p<\infty$ the $p$-convexification $X^{(p)}$ of $X$ is the space of all $f \in L_{0}(I)$ such that $|f|^{p} \in X$ with the norm

$$
\|f\|_{X^{(p)}}:=\left\||f|^{p}\right\|_{X}^{1 / p} .
$$

It is easy to check that $X^{(p)}$ is also a normed ideal space on $I$ [61, p. 53].

Let $X=(X,\|\cdot\|)$ be a normed ideal space on $I$. The Köthe dual (or associated space) $X^{\prime}$ is the space of all $f \in L_{0}(I)$ such that the associated norm

$$
\|f\|^{\prime}:=\sup _{g \in X,\|g\|_{X} \leq 1} \int_{I}|f(x) g(x)| d x
$$

is finite. The Köthe dual $X^{\prime}=\left(X^{\prime},\|\cdot\|^{\prime}\right)$ is a Banach ideal space such that $X^{\prime} \hookrightarrow X^{*}$, where $X^{*}$ is the Banach dual space. Moreover, $X \hookrightarrow X^{\prime \prime}$ with $\|f\|^{\prime \prime} \leq\|f\|$ for all $f \in X$, and $X$ is isometric to $X^{\prime \prime}$ if and only if this space has the Fatou property, that is, if $0 \leq f_{n} \nearrow f$ a.e. on $I$ and $\sup _{n \in \mathbf{N}}\left\|f_{n}\right\|_{X}<\infty$, then $f \in X$ and $\left\|f_{n}\right\|_{X} \nearrow\|f\|_{X}$.

For a normed ideal space $X=(X,\|\cdot\|)$ on $I$ with the Köthe dual $X^{\prime}$ we have the following Hölder type inequality: if $f \in X$ and $g \in X^{\prime}$, then $f g$ is integrable and

$$
\int_{I}|f(x) g(x)| d x \leq\|f\|_{X}\|g\|_{X^{\prime}}
$$

If $1 \leq p \leq \infty$, then the conjugate number $p^{\prime}$ to $p$ is given by $\frac{1}{p^{\prime}}+\frac{1}{p}=1$. A function $f$ from a normed ideal space $X$ on $I$ is said to have absolutely continuous norm in $X$ if, for any decreasing sequence of $\Sigma$-measurable sets $A_{n} \subset I$ with empty intersection, we have $\left\|f \chi_{A_{n}}\right\| \rightarrow 0$ as $n \rightarrow \infty$. The set of all functions in $X$ with absolutely continuous norm is denoted by $X_{a}$. If $X_{a}=X$, then the space $X$ itself is said to have absolutely continuous norm. For a normed ideal space $X$ with an absolutely continuous norm, the Köthe dual $X^{\prime}$ and the Banach dual space $X^{*}$ coincide. Moreover, a Banach ideal space $X$ is reflexive if and only if both $X$ and its associate space $X^{\prime}$ have absolutely continuous norms. 
By a symmetric or rearrangement invariant space we mean a Banach function lattice $X$ on $I$ satisfying the additional property: if $g^{*}(t)=f^{*}(t)$ for all $t>0, f \in X$ and $g \in L_{0}(I)$, then $g \in X$ and $\|g\|_{X}=\|f\|_{X}$ (cf. [18], [53]). Here and next $f^{*}$ denotes the non-increasing rearrangement of $|f|$ defined by

$$
f^{*}(t)=\inf \{\lambda>0: m(\{x \in I:|f(x)|>\lambda\}) \leq t\}, \quad t>0,
$$

where $m$ is the usual Lebesgue measure (see [53, pp. 78-79] or [18, Theorem 6.2, pp. 74-75]). Moreover, in what follows $\chi_{A}$ is the characteristic function of a set $A \subset \mathbb{R}$.

For general properties of normed ideal and symmetric spaces we refer to the books Krein-Petunin-Semenov [53], Bennett-Sharpley [18], Lindenstrauss-Tzafriri [61] and Maligranda [66].

3. Basic properties of Cesàro and Copson spaces. In the following theorem we collect the simplest properties of Cesàro function spaces $\operatorname{Ces}_{p}(I)$ for both cases $I=[0,1]$ and $I=[0, \infty)$.

THEOREM 3.1.

(a) If $1<p \leq \infty$, then $\operatorname{Ces}_{p}(I)$ are ideal Banach function spaces which are not rearrangement invariant. Moreover, Ces $s_{1}[0,1]=L_{1}(\ln 1 / t)$ isometrically and $\operatorname{Ces}_{1}[0, \infty)=\{0\}$.

(b) The spaces $\mathrm{Ces}_{p}(I)$ are separable for $1<p<\infty$ and $\mathrm{Ces}_{\infty}(I)$ is non-separable.

(c) If $1<p \leq \infty$, then $L_{p}(I) \stackrel{p^{\prime}}{\rightarrow} \operatorname{Ces}_{p}(I)$ and the embedding is strict.

(d) $L_{\infty}(I) \stackrel{1}{\hookrightarrow} \operatorname{Ces}_{\infty}(I), \operatorname{Ces}_{\infty}[0,1] \stackrel{1}{\hookrightarrow} L_{1}[0,1]$ and $\operatorname{Ces}_{p}(I) \not \subset L_{1}(I)$ for every $1<p<\infty$.

(e) If $1 \leq p<q \leq \infty$, then $C e s_{q}[0,1] \stackrel{1}{\hookrightarrow} C e s_{p}[0,1]$ and the embedding is strict.

(f) The spaces $\operatorname{Ces}_{p}[0,1], 1 \leq p \leq \infty$ and Ces $s_{p}[0, \infty), 1<p \leq \infty$, are not reflexive.

(g) The spaces $\mathrm{Ces}_{p}(I)$ for $1<p<\infty$ are strictly convex, that is, if $\|f\|_{C(p)}=$ $\|g\|_{C(p)}=1$ and $f \neq g$, then $\left\|\frac{f+g}{2}\right\|_{C(p)}<1$.

Proof. (a): We begin with the proof of the isometric equality $\operatorname{Ces}_{1}[0,1]=L_{1}\left(\ln \frac{1}{t}\right)$. In fact,

$$
\begin{aligned}
\|f\|_{C(1)} & =\int_{0}^{1}\left(\frac{1}{x} \int_{0}^{x}|f(t)| d t\right) d x=\int_{0}^{1}\left(\int_{t}^{1} \frac{1}{x} d x\right)|f(t)| d t \\
& =\int_{0}^{1}|f(t)| \ln \frac{1}{t} d t=\|f\|_{L_{1}(\ln 1 / t)} .
\end{aligned}
$$

Next, if $f \in L_{0}[0, \infty)$ and $f(x) \neq 0$ for $x \in A$ with $m(A)>0$, then there exists sufficiently large $a>0$ such that $\delta=\int_{0}^{a}|f(t)| d t>0$. Therefore, for $b>a$, it yields that

$$
\|f\|_{C(1)} \geq \int_{0}^{b}\left(\frac{1}{x} \int_{0}^{x}|f(t)| d t\right) d x \geq \int_{a}^{b}\left(\frac{1}{x} \int_{0}^{a}|f(t)| d t\right) d x=\delta \ln \frac{b}{a} \rightarrow \infty \text { as } b \rightarrow \infty .
$$

Thus, $f \notin C e s_{1}[0, \infty)$.

Let us show that the spaces $\operatorname{Ces}_{p}[0,1]$ are not rearrangement invariant. Consider the functions $f_{h}(t):=\chi_{(1-h, 1]}(t)$ and $g_{h}(t):=f_{h}^{*}(t)=\chi_{(0, h]}(t)(0<h<1)$. Since 
$\int_{0}^{x}\left|f_{h}(t)\right| d t=0$ if $x \leq 1-h$ and $\int_{0}^{x}\left|f_{h}(t)\right| d t=x-1+h$ if $1-h<x \leq 1$, then in the case $1 \leq p<\infty$ we have

$$
\left\|f_{h}\right\|_{C(p)}^{p}=\int_{1-h}^{1}\left(\frac{x-1+h}{x}\right)^{p} d x=\int_{1-h}^{1}\left(1-\frac{1-h}{x}\right)^{p} d x \leq h^{1+p} .
$$

On the other hand, $\int_{0}^{x}\left|g_{h}(t)\right| d t=x$ if $0<x \leq h$, and hence $\left\|g_{h}\right\|_{C(p)}^{p} \geq h$. Similarly, if $p=\infty$, we have $\left\|f_{h}\right\|_{C(\infty)} \leq h$ and $\left\|g_{h}\right\|_{C(\infty)}=1(0<h<1)$. Thus, in both cases

$$
\frac{\left\|g_{h}\right\|_{C(p)}}{\left\|f_{h}\right\|_{C(p)}} \geq \frac{1}{h} \rightarrow+\infty \quad \text { as } \quad h \rightarrow 0^{+},
$$

and we come to desired result.

Note, in addition, that a direct calculation shows that $f(x)=(1-x)^{-1}$ is an explicit example of a function from the space $C e s_{p}[0,1]$, with $1 \leq p<\infty$, such that its rearrangement $f^{*}(x)=x^{-1}$ does not belong to this space (in the case $p=\infty$ we may take the function $f(x)=(1-x)^{-1 / 2}$ and its rearrangement $\left.f^{*}(x)=x^{-1 / 2}\right)$.

Arguing in a completely analogous way, we can do this in the case when $I=[0, \infty)$.

Properties in (b) follow from the fact that $\operatorname{Ces}_{p}(I)$ has absolutely continuous norm if and only if $p<\infty$. Embedding (c) follows directly from the classical Hardy inequality (cf. [41, Theorems 326 and 327] and [54, Chapter 3]). The proof of properties (d) and (e) is direct and routine. Property (f) follows from the fact that for $1<p \leq \infty$ the space $\operatorname{Ces}_{p}(I)$ contains a copy of $L_{1}(I)$ (cf. Part 5) and therefore, in particular, it cannot be reflexive. Of course, $\operatorname{Ces}_{1}[0,1]=L_{1}(\ln 1 / t)$ is not reflexive as well. Finally, for the proof of $(\mathrm{g})$ we refer to $[8]$.

The norms in Cesàro sequence and function spaces are defined by the Cesàro operators $C_{d} x(n)=\frac{1}{n} \sum_{k=1}^{n}\left|x_{k}\right|$ and $C f(x)=\frac{1}{x} \int_{0}^{x}|f(t)| d t$, respectively. By using conjugate operators to them, that is, the operators $C_{d}^{*} x(n)=\sum_{k=n}^{\infty} \frac{\left|x_{k}\right|}{k}$ and $C^{*} f(x)=\int_{(x, \infty) \cap I} \frac{|f(t)|}{t} d t$ we can define the so-called Copson sequence and function spaces.

For $1 \leq p<\infty$ the Copson sequence spaces cop $p$ are the sets of real sequences $x=\left\{x_{k}\right\}$ such that

$$
\|x\|_{\operatorname{cop}(p)}=\left[\sum_{n=1}^{\infty}\left(\sum_{k=n}^{\infty} \frac{\left|x_{k}\right|}{k}\right)^{p}\right]^{1 / p}<\infty,
$$

and the Copson function spaces $\operatorname{Cop}_{p}(I)$ are the classes of Lebesgue measurable real functions $f$ on $I=[0, \infty)$ or $I=[0,1]$ such that

$$
\|f\|_{C o p(p)}=\left[\int_{0}^{\infty}\left(\int_{x}^{\infty} \frac{|f(t)|}{t} d t\right)^{p} d x\right]^{1 / p}<\infty, \quad \text { for } \quad I=[0, \infty),
$$

and

$$
\|f\|_{C o p(p)}=\left[\int_{0}^{1}\left(\int_{x}^{1} \frac{|f(t)|}{t} d t\right)^{p} d x\right]^{1 / p}<\infty, \quad \text { for } \quad I=[0,1] .
$$

We have $\operatorname{cop}_{1}=l_{1}, \operatorname{Cop}_{1}(I)=L_{1}(I)$ and by the classical Copson inequalities (cf. [41, Theorems 328 and 331], [17, p. 25] and [54, p. 159]), which are valid for $1<p<\infty$, we obtain $l_{p} \stackrel{p}{\hookrightarrow} \operatorname{cop}_{p}, L_{p}(I) \stackrel{p}{\hookrightarrow} \operatorname{Cop}_{p}(I)$. 
We can define similarly the spaces $\operatorname{cop}_{\infty}$ and $C o p_{\infty}$ but, as it is easy to see, $\operatorname{cop}_{\infty}=l_{1}(1 / k)$ and $\operatorname{Cop}_{\infty}(I)=L_{1}(1 / t)(I)$. Moreover, for $I=[0,1]$ we have $L_{p} \stackrel{p}{\hookrightarrow}$ $\mathrm{Cop}_{p} \stackrel{1}{\hookrightarrow} \mathrm{Cop}_{1}=L_{1}$.

THEOREM 3.2 .

(a) If $1<p<\infty$, then

$$
\operatorname{ces}_{p}=\operatorname{cop}_{p} \text { and } \operatorname{Ces}_{p}[0, \infty)=\operatorname{Cop}_{p}[0, \infty) .
$$

(b) If $1<p \leq \infty$, then

$$
\operatorname{Cop}_{p}[0,1] \stackrel{p^{\prime}}{\rightarrow} \operatorname{Ces}_{p}[0,1] \text { and } \operatorname{Cop}_{p}[0,1] \neq \operatorname{Ces}_{p}[0,1] .
$$

Proof. (a): The first equality in (1) was proved by Bennett (cf. [17], Theorems 4.5 and 6.6) and the second one in our paper [11], Theorem 1(ii). In fact, by the Fubini theorem, for arbitrary $f \in L_{0}[0, \infty)$ we have

$$
C C^{*} f(x)=C f(x)+C^{*} f(x)=C^{*} C f(x), x>0,
$$

and using already mentioned Hardy's and Copson's inequalities we obtain

$$
\|f\|_{C(p)}=\|C f\|_{L_{p}} \leq\left\|C f+C^{*} f\right\|_{L_{p}}=\left\|C^{*} C f\right\|_{L_{p}} \leq p\|C f\|_{L_{p}}=p\|f\|_{C(p)}
$$

and

$$
\|f\|_{C o p(p)}=\left\|C^{*} f\right\|_{L_{p}} \leq\left\|C f+C^{*} f\right\|_{L_{p}}=\left\|C C^{*} f\right\|_{L_{p}} \leq p^{\prime}\left\|C^{*} f\right\|_{L_{p}}=p^{\prime}\|f\|_{C o p(p)} .
$$

Therefore

$$
(1-1 / p)\|f\|_{C(p)} \leq\|f\|_{C o p(p)} \leq p\|f\|_{C(p)} .
$$

(b): This part was proved in [11], Theorem 1(iii). In the case [0,1] only the first equality in (3) holds and therefore the only one embedding (see (2)) is true.

4. Dual spaces of Cesàro function spaces. In the prize problem of the Dutch Mathematical Society (1968), it was asked to determine the dual (Banach dual) of Cesàro sequence and function spaces. The problem in the case of sequence spaces was solved by Jagers in 1974. In 1987, Sy, Zhang and Yee have used the result of Jagers to get a description of the Banach dual of Cesàro function spaces $\operatorname{Ces}_{p}[0, \infty)$, which, however, is rather complicated and a bit implicit.

Another description based on a factorization idea due to G. Bennett [17] was given in 2009 in our paper [8]. Surprisingly, the obtained results look quite differently in the cases $I=[0,1]$ and $I=[0, \infty)$.

Firstly, we will consider a simpler case $I=[0, \infty)$. Let us define the Banach function lattice $D_{p}=D_{p}[0, \infty), 1 \leq p<\infty$, by the norm

$$
\|f\|_{D(p)}=\|\tilde{f}\|_{L_{p}[0, \infty)}, \quad \text { where } \tilde{f}(x)=\operatorname{ess~sup~}_{t \in[x, \infty)}|f(t)| .
$$

THEOREM 4.1. If $1<p<\infty$, then

$$
\left(\operatorname{Ces}_{p}[0, \infty)\right)^{*}=\left(\operatorname{Ces}_{p}[0, \infty)\right)^{\prime}=D_{p^{\prime}}[0, \infty), \quad p^{\prime}=\frac{p}{p-1},
$$

with $\|f\|_{C(p)^{\prime}} \leq p^{\prime}\|f\|_{D\left(p^{\prime}\right)} \leq\left(p^{\prime}\right)^{2}\|f\|_{C(p)^{\prime}}$. 
To explain the idea of the proof of this theorem, let us denote by $G_{p}=G_{p}[0, \infty)$, $1 \leq p<\infty$, the $p$-convexification of the space $\operatorname{Ces}_{\infty}[0, \infty)$, that is, the space with the norm

$$
\|f\|_{G(p)}=\left\||f|^{p}\right\|_{C(\infty)}^{1 / p}=\sup _{x>0}\left(\frac{1}{x} \int_{0}^{x}|f(t)|^{p} d t\right)^{1 / p} .
$$

The proof of Theorem 4.1 is based on using the following factorization result which was obtained also in [8].

Proposition 4.2. Let $I=[0, \infty)$.

(a) If $1<p<\infty$, then

$$
\operatorname{Ces}_{p}(I)=L_{p}(I) \cdot G_{p^{\prime}}(I),
$$

that is, $f \in \operatorname{Ces}_{p}(I)$ if and only if $f=g h$ with $g \in L_{p}(I), h \in G_{p^{\prime}}(I)$ and

$$
\|f\|_{C(p)} \approx \inf \|g\|_{p}\|h\|_{G\left(p^{\prime}\right)},
$$

where infimum is taken over all factorizations $f=g h$ with $g \in L_{p}(I), h \in G_{p^{\prime}}(I)$.

(b) If $1 \leq p<\infty$, then

$$
D_{p}(I) \cdot G_{p}(I)=L_{p}(I)
$$

and

$$
\|f\|_{L_{p}}=\inf \left\{\|g\|_{D(p)}\|h\|_{G(p)}: f=g h, g \in D_{p}(I), h \in G_{p}(I)\right\} .
$$

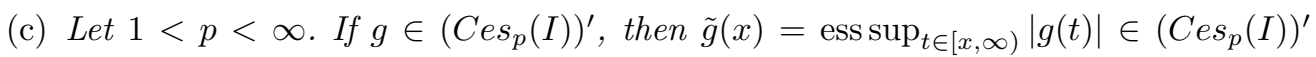
and

$$
\|\tilde{g}\|_{C(p)^{\prime}} \leq 8\|g\|_{C(p)^{\prime}} .
$$

REMARK 4.3. From Proposition 4.2(b), applied in the case when $p=1$, it follows in particular that

$$
\left(\operatorname{Ces}_{\infty}[0, \infty)\right)^{\prime}=\left(G_{1}[0, \infty)\right)^{\prime}=D_{1}[0, \infty),
$$

which is an analogue of the result proved by Luxemburg-Zaanen in 1965 for $I=[0,1]$ (cf. [65, Theorem 4.4]):

$$
\left(\operatorname{Ces}_{\infty}[0,1]\right)^{\prime}=\tilde{L_{1}}[0,1], \quad \text { where }\|f\|_{\tilde{L_{1}}}=\|\tilde{f}\|_{L_{1}[0,1]} \quad \text { and } \quad \tilde{f}(x)=\operatorname{essup}_{t \in[x, 1]}|f(t)| .
$$

REMARK 4.4. In fact, the factorization equality from Proposition 4.2 (b) holds for more general spaces. Let $w$ be a positive weight function on $I=[0, \infty)$ and let $1 \leq p<\infty$. We define the weighted spaces $D_{p, w}$ and $G_{p, w}$ on $I=[0, \infty)$ by the norms

$$
\|f\|_{D(p, w)}=\left(\int_{0}^{\infty} \tilde{f}(x)^{p} w(x) d x\right)^{1 / p}, \quad \text { where } \tilde{f}(x)=\operatorname{essip}_{t \in[x, \infty)}|f(t)|,
$$

and

$$
\|f\|_{G(p, w)}=\sup _{x>0}\left(\frac{1}{W(x)} \int_{0}^{x}|f(t)|^{p} d t\right)^{1 / p}, \quad \text { where } W(x)=\int_{0}^{x} w(t) d t,
$$

respectively. Then we have

$D_{p, w} \cdot G_{p, w}=L_{p} \quad$ and $\quad\|f\|_{L_{p}}=\inf \left\{\|g\|_{D(p, w)}\|h\|_{G(p, w)}: f=g h, g \in D_{p, w}, h \in G_{p, w}\right\}$. 
Proof of Theorem 4.1. Firstly, we show that the following embedding holds

$$
D_{p^{\prime}}[0, \infty) \stackrel{1}{\hookrightarrow}\left(L_{p}[0, \infty) \cdot G_{p^{\prime}}[0, \infty)\right)^{\prime} .
$$

In fact, let $f \in D_{p^{\prime}}$ and $g \in L_{p} \cdot G_{p^{\prime}}$. Then $g=h \cdot k$ with $h \in L_{p}$ and $k \in G_{p^{\prime}}$. By the Hölder-Rogers inequality and the embedding $D_{p^{\prime}} \cdot G_{p^{\prime}} \stackrel{1}{\hookrightarrow} L_{p^{\prime}}$ (see Proposition 4.2(b)), we obtain

$$
\|f g\|_{L_{1}}=\|f h k\|_{L_{1}} \leq\|h\|_{L_{p}}\|f k\|_{L_{p^{\prime}}} \leq\|h\|_{L_{p}}\|k\|_{G\left(p^{\prime}\right)}\|f\|_{D\left(p^{\prime}\right)},
$$

from which it follows that $D_{p^{\prime}} \subset\left(L_{p} \cdot G_{p^{\prime}}\right)^{\prime}$ and $\|f\|_{\left(L_{p} \cdot G_{p^{\prime}}\right)^{\prime}} \leq\|f\|_{D\left(p^{\prime}\right)}$. Combining this with the equality $\mathrm{Ces}_{p}=L_{p} \cdot G_{p^{\prime}}$ (see Proposition $4.2(\mathrm{a})$ ), we infer

$$
D_{p^{\prime}}[0, \infty) \stackrel{p^{\prime}}{\hookrightarrow}\left(\operatorname{Ces}_{p}[0, \infty)\right)^{\prime} .
$$

To prove the converse, take $f \in\left(C e s_{p}\right)^{\prime}$. Since $\tilde{f} \geq|f|$ and $D_{p^{\prime}}$ is a Banach lattice, then by Proposition 4.2 (c), we may (and will) assume that $f$ is a non-negative decreasing function on $(0, \infty)$, i. e., $f=\tilde{f}$. Then, by the Hardy inequality,

$$
\begin{aligned}
\|f\|_{D\left(p^{\prime}\right)} & =\|f\|_{L_{p^{\prime}}}=\sup \left\{\int_{0}^{\infty}|f(x) g(x)| d x:\|g\|_{L_{p}} \leq 1\right\} \\
& \leq p^{\prime} \sup \left\{\int_{0}^{\infty}|f(x) g(x)| d x:\|g\|_{C(p)} \leq 1\right\}=p^{\prime}\|f\|_{\left(C e s_{p}\right)^{\prime}} .
\end{aligned}
$$

Therefore, $f \in D_{p^{\prime}}$ and $\left(\operatorname{Ces}_{p}[0, \infty)\right)^{\prime} \stackrel{p^{\prime}}{\rightarrow} D_{p^{\prime}}[0, \infty)$.

REMARK 4.5. Another proof of Theorem 4.1 was given by Kerman-Milman-Sinnamon [49, Theorem D]. In contrast to factorization methods, it is likely that their method of the proof works only in the case $I=[0, \infty)$.

Now, let us consider in a sense more interesting case $I=[0,1]$. Recall that the space $K:=C e s_{\infty}[0,1]$ was introduced by Korenblyum, Krĕ̌n and Levin [52 already in 1948. As it was mentioned before (see Remark 4.3), the Köthe dual space $K^{\prime}$ was found by Luxemburg-Zaanen a long time ago. Moreover, earlier (1954) Tandori [87] gave a similar description of the dual space of $K_{a}$ (the space of all elements from $K$ having absolutely continuous norm in $K):\left(K_{a}\right)^{*}=\tilde{L}_{1}$ with equality of the norms.

Let us consider the Banach function lattice $U_{p}=U_{p}[0,1]$ with the norm

$$
\|f\|_{U(p)}=\left[\int_{0}^{1}\left(\frac{\tilde{f}(x)}{1-x}\right)^{p} d x\right]^{1 / p}, \quad 1<p<\infty,
$$

where, as above, $\tilde{f}(x)=\operatorname{ess}_{\sup }|f(t)|$.

THEOREM 4.6. If $1<p<\infty$, then

$$
\left(\operatorname{Ces}_{p}[0,1]\right)^{*}=\left(\operatorname{Ces}_{p}[0,1]\right)^{\prime}=U_{p^{\prime}}[0,1], \quad p^{\prime}=\frac{p}{p-1} .
$$

A rather surprised feature of the formula (7) is the fact that the norm of $U_{p^{\prime}}[0,1]$ contains a weight with a singularity at $x=1$. To explain this point, we observe that, in contrast to $L_{p}$-spaces, the restriction of the space $C e s_{p}[0, \infty)$ to $[0,1]$ does not give the 
space $C e s_{p}[0,1]$. In fact, if $f \in C e s_{p}[0, \infty)$ and $\operatorname{supp} f \subset[0,1]$, then it is not hard to check that

$$
\|f\|_{C e s_{p}[0, \infty)}^{p}=\|f\|_{\operatorname{Ces}_{p}[0,1)}^{p}+\frac{1}{p-1}\|f\|_{L_{1}[0,1]}^{p},
$$

which means

$$
\left.C e s_{p}[0, \infty)\right|_{[0,1]}=C e s_{p}[0,1] \cap L_{1}[0,1] .
$$

Since there are not integrable on $[0,1]$ functions, which belong to the space $C e s_{p}[0,1]$, we conclude that $\left.\operatorname{Ces}_{p}[0, \infty)\right|_{[0,1]} \neq \operatorname{Ces}_{p}[0,1]$. Thus, $\operatorname{Ces}_{p}[0,1]$ is not a subspace of the space $C e s_{p}[0, \infty)$.

In the proof of Theorem 4.6 we make use of the Banach ideal space $V_{p}=V_{p}[0,1]$, $1<p<\infty$, given by the norm

$$
\|f\|_{V(p)}=\sup _{0<x \leq 1}\left[\frac{\left(1-x^{1 /(p-1)}\right)^{p-1}}{x} \int_{0}^{x}|f(t)|^{p} d t\right]^{1 / p}
$$

and of the following factorization result.

Proposition 4.7. Let $1<p<\infty$.

(a) $C e s_{p}[0,1] \hookrightarrow L_{p}[0,1] \cdot V_{p^{\prime}}[0,1]$ and

$$
\inf \left\{\|g\|_{L_{p}}\|h\|_{V\left(p^{\prime}\right)}: f=g \cdot h, g \in L_{p}[0,1], h \in V_{p^{\prime}}[0,1]\right\} \leq(p-1)^{1 / p}\|f\|_{C(p)} .
$$

(b) $U_{p}[0,1] \cdot V_{p}[0,1] \hookrightarrow L_{p}[0,1]$ with

$$
\|f\|_{L_{p}} \leq \max (1, p-1) \inf \left\{\|g\|_{U(p)}\|h\|_{V(p)}: f=g \cdot h, g \in U_{p}[0,1], h \in V_{p}[0,1]\right\} .
$$

(c) $U_{p}[0,1] \hookrightarrow\left(V_{p}[0,1] \cdot L_{p^{\prime}}[0,1]\right)^{\prime}$ and $\|f\|_{\left(V(p) \cdot L_{p^{\prime}}\right)^{\prime}} \leq \max (1, p-1)\|f\|_{U(p)}$ for all $f \in U_{p}[0,1]$.

Let us denote by $K^{(p)}(I)$ the $p$-convexification of the space $C e s_{\infty}(I)$, where $I=[0,1]$ or $I=[0, \infty)$. Clearly, $K^{(p)}(I)$ is a non-separable space.

REMARK 4.8. In the embedding $\operatorname{Ces}_{p}[0,1] \hookrightarrow L_{p}[0,1] \cdot V_{p^{\prime}}[0,1]$ we cannot take instead of the space $V_{p^{\prime}}[0,1]$, where the weight $w(x)=\left(1-x^{p-1}\right)^{1 /(p-1)}$ appeared, the corresponding space without this weight, that is, $K^{\left(p^{\prime}\right)}:=K^{\left(p^{\prime}\right)}[0,1]$. In fact, if the embedding $C e s_{p}[0,1] \subset L_{p}[0,1] \cdot K^{\left(p^{\prime}\right)}$ would be valid, then combining it with the fact that

$$
L_{p} \cdot K^{\left(p^{\prime}\right)} \subset L_{p}[0,1] \cdot L_{p^{\prime}}[0,1]=L_{1}[0,1]
$$

we will have a contradiction because of $C e s_{p}[0,1]$ is not embedded into $L_{1}[0,1]$ (cf. Theorem 3.1 (d)).

Problem 1. Identify the Köthe dual $\left[K^{(p)}(I)\right]^{\prime}$ for $1<p<\infty$.

Let us mention here that from the Lozanovskiı duality theorem for Calderón construction (cf. [64]; see also [66, pp. 179 and 184]) it follows that

$$
\left[K^{(p)}\right]^{\prime}=\left[K^{1 / p}\left(L_{\infty}\right)^{1-1 / p}\right]^{\prime}=\left(K^{\prime}\right)^{1 / p}\left(L_{1}\right)^{1-1 / p}=\left(D_{1}\right)^{1 / p}\left(L_{1}\right)^{1-1 / p},
$$

but we do not know an identification of the spaces from the right hand side of this equality (see also the results related to Köthe dual of a general $p$-convexification in [50, pages 7-9]). 
Kamińska and Kubiak [46] presented recently an isometric representation of the dual space of Cesàro function spaces $C_{p, w}, 1<p<\infty$, with a positive weight function $w$ on $I$ :

$$
\|f\|_{C_{p, w}}=\left[\int_{I}\left(w(x) \int_{0}^{x}|f(t)| d t\right)^{p} d x\right]^{1 / p},
$$

assuming that $w$ satisfies the conditions: $\int_{t}^{1} w(s)^{p} d s<\infty$ for all $t \in(0,1)$ and $\int_{0}^{1} w(s)^{p} d s=\infty$ in the case $I=[0,1]$ (in the case $I=[0, \infty$ ) the assumptions are $\int_{t}^{\infty} w(s)^{p} d s<\infty$ for all $t \in(0, \infty)$ and $\left.\int_{0}^{\infty} w(s)^{p} d s=\infty\right)$. A description given in [46] resembles the approach of Jagers [44] for sequence spaces, however, the techniques are more involved due to necessity of dealing with measurable functions instead of sequences. As applications Kamińska and Kubiak showed that every slice of the unit ball of $C_{p, w}$ has diameter 2 which implies that $C_{p, w}$ are not dual spaces, do not have the Radon-Nikodym property, and they are not locally uniformly convex (a Banach space $(X,\|\cdot\|)$ is called $l o$ cally uniformly convex if, for any $x \in X,\|x\|=1$, and arbitrary sequence $\left\{x_{n}\right\},\left\|x_{n}\right\| \leq 1$ $(n \in \mathbb{N})$, the assumption $\lim _{n \rightarrow \infty}\left\|x+x_{n}\right\|=2$ implies that $\left.\lim _{n \rightarrow \infty}\left\|x-x_{n}\right\|=0\right)$.

Recently, in [12] (see Theorem 3), another much shorter proof of two first properties in the case of $\operatorname{Ces}_{p}(I)$ was presented. As is shown there, on this space an equivalent norm $\|\cdot\|_{C(p)}^{*}$ can be introduced such that the space $\left(C_{e s}(I),\|\cdot\|_{C(p)}^{*}\right)$ contains a closed subspace isometric to the space $L_{1}[0,1]$. Thus, from the well-known BessagaPełczyński theorem [20] it follows that $\operatorname{Ces}_{p}(I)$ cannot be a dual space and does not have the Radon-Nikodym property (note that, by Talagrand theorem [72, Corollary 5.4.21], a separable Banach lattice is the dual Banach lattice if and only if it has the RadonNikodym property).

5. $\boldsymbol{l}_{\boldsymbol{q}}$-copies in Cesàro function spaces. One of the most important characteristics of the geometric structure of a Banach space is the existence of (complemented) $l_{q}$-copies, that is, of (complemented) subspaces isomorphic to the space $l_{q}, 1 \leq q \leq \infty$, in the space in question (see, for example, [1, Chapters 6, 10 and 11]).

We begin with the following results which were proved in [7] and [8]. Let us recall that a Banach space $X$ contains an asymptotically isometric copy of $l_{1}$ if there exist a null sequence $\left\{\varepsilon_{n}\right\}_{n=1}^{\infty}, 0<\varepsilon_{n}<1$, and a sequence $\left\{x_{n}\right\}_{n=1}^{\infty} \subset X$ such that

$$
\sum_{n=1}^{\infty}\left(1-\varepsilon_{n}\right)\left|\alpha_{n}\right| \leq\left\|\sum_{n=1}^{\infty} \alpha_{n} x_{n}\right\|_{X} \leq \sum_{n=1}^{\infty}\left|\alpha_{n}\right|
$$

for all $\left\{\alpha_{n}\right\}_{n=1}^{\infty} \in l_{1}$. This notion was introduced by Dowling and Lennard in [37].

TheOrem 5.1. Let $1 \leq p \leq \infty$ if $I=[0,1]$ and $1<p \leq \infty$ if $I=[0, \infty)$.

(a) $\operatorname{Ces}_{p}(I)$ contains an asymptotically isometric copy of $l_{1}$;

(b) $\operatorname{Ces}_{p}(I)$ contains an order isomorphic and complemented copy of $L_{1}(I)$;

(c) $\operatorname{Ces}_{p}(I)$ contains an order isomorphic and complemented copy of $l_{p}$.

Proof. (a): Setting $\varepsilon_{n}=1-\left(2\left(1-2^{-n}\right)^{1-p}-1\right)^{-1 / p}, a_{n}=2^{1 /(1-p)}\left(1-2^{-n}\right)$ if $1 \leq p<\infty$ and $\varepsilon_{n}=2^{-n}, a_{n}=1-2^{-n}$ if $p=\infty$, we define $f_{n}=g_{n} /\left\|g_{n}\right\|_{C(p)}$, where $g_{n}=\chi_{\left[a_{n}, a_{n+1}\right)}$ 
$(n=1,2, \ldots)$. Then direct estimations show that

$$
\sum_{n=1}^{\infty}\left(1-\varepsilon_{n}\right)\left|\alpha_{n}\right| \leq\left\|\sum_{n=1}^{\infty} \alpha_{n} f_{n}\right\|_{C(p)} \leq \sum_{n=1}^{\infty}\left|\alpha_{n}\right|,
$$

and assertion (a) is proved.

(b): It can be easily checked that, for every $h \in(0,1 / 2)$, the subspace $X_{h}$ of $\operatorname{Ces}_{p}(I)$ defined by

$$
X_{h}:=\left\{f \in \operatorname{Ces}_{p}(I): \operatorname{supp} f \subset[h, 1-h]\right\}
$$

is isomorphic to $L_{1}[h, 1-h]$ (and therefore to $L_{1}(I)$ ). This follows from the fact that $\|f\|_{C(p)} \approx\|f\|_{L_{1}}$ for all $f \in X_{h}$, with a constant which depends only on $h$. Since the orthogonal projection $P f:=f \cdot \chi_{[h, 1-h]}$ is bounded in $\operatorname{Ces}_{p}(I)$, the subspace $X_{h}$ is complemented in $\operatorname{Ces}_{p}(I)$.

(c): If $h_{n}=\chi_{\left[2^{-n-1}, 2^{-n}\right]}(n=1,2, \ldots)$, then $\left\|h_{n}\right\|_{C(p)} \approx\left\|h_{n}\right\|_{L_{p}} \approx 2^{-n / p}$ and for $\widetilde{h_{n}}=h_{n} /\left\|h_{n}\right\|_{C(p)}$ we have

$$
\left\|\sum_{n=1}^{\infty} a_{n} \widetilde{h_{n}}\right\|_{C(p)} \approx\left(\sum_{n=1}^{\infty}\left|a_{n}\right|^{p}\right)^{1 / p}
$$

(with a natural modification for $p=\infty$ ), where the constant of equivalence depends only on $p$. Therefore, the closed linear span $\left[\widetilde{h_{n}}\right]$ is order isomorphic to $l_{p}$. Since the orthogonal projection onto $\left[\widetilde{h_{n}}\right]$ is bounded in $\operatorname{Ces}_{p}(I)$, this subspace is complemented.

Now, we proceed with some applications of Theorem 5.1

A Banach space $X=(X,\|\cdot\|)$ has the fixed point property for nonexpansive mappings or shortly fixed point property (FPP) if every nonexpansive mapping $T: C \rightarrow C$ (means $\|T x-T y\| \leq\|x-y\|$ for all $x, y \in C)$ of any closed bounded convex subset $C$ of $X$ has a fixed point, that is, there exists a $x_{0} \in C$ such that $T\left(x_{0}\right)=x_{0}$. Similarly the weak fixed point property (WFPP) can be defined by replacing the class of closed and bounded subsets by the class of weakly compact subsets.

In 1999-2000, it was proved by Cui-Hudzik [26], Cui-Hudzik-Li [29] and Cui-MengPłuciennik [31] that the Cesàro sequence spaces $c e s_{p}$ for $1<p<\infty$ have the fixed point property (cf. also [24, Part 9]). In contrast to this, in [7] the following result was obtained.

Corollary 5.2. Let $1 \leq p \leq \infty$ if $I=[0,1]$ and let $1<p \leq \infty$ if $I=[0, \infty)$. The Cesàro function spaces $\operatorname{Ces}_{p}(I)$ and their dual spaces $\mathrm{Ces}_{p}(I)^{*}$ fail to have the fixed point property.

Proof. In [36, Dowling and Lennard proved that a Banach space containing an asymptotically isometric copy of $l_{1}$ fails to have the fixed point property. Therefore, from Theorem 5.1(a) it follows that $\operatorname{Ces}_{p}(I) \notin F P P$. Moreover, by the Dilworth-Girardi-Hagler result [34], a Banach space $X$ contains an asymptotically isometric copy of $l_{1}$ if and only if the dual space $X^{*}$ contains an isometric copy of $L_{1}[0,1]$. Therefore, again by Theorem $5.1(\mathrm{a}),\left(\operatorname{Ces}_{p}(I)\right)^{*}$ contains an isometric copy of $L_{1}[0,1]$. Since the latter space has not the fixed point property we conclude that $\left(\operatorname{Ces}_{p}(I)\right)^{*} \notin F P P$ as well.

Of course, $X \in F P P$ implies that $X \in W F P P$ and in the class of reflexive spaces these two properties are equivalent. It is known that uniformly convex Banach spaces have 
the FPP (Browder-Göhde-Kirk 1965) and uniformly non-square Banach spaces have the FPP (García-Falset, Llorens-Fuster, Mazcunán-Navarro 2006), thus all classical reflexive spaces have the FPP. On the other hand, there are examples of classical nonreflexive spaces $c_{0}, l_{1}, L_{1}[0,1], L_{\infty}[0,1], C[0,1]$ and $L_{p, 1}[0, \infty)$ which fail the fixed point property for nonexpansive mappings. We also have that $l_{1}, c_{0} \in W F P P \backslash F P P$ and $L_{1}[0,1] \notin W F P P$ (Alspach 1981).

In connection with Corollary 5.2 it is natural to ask what one can say about the weak fixed point property of the Cesàro spaces $\operatorname{Ces}_{p}(I)$ (see [7, p. 4293]). Note that the space $\operatorname{Ces}_{1}[0,1]=L_{1}(\ln 1 / t)[0,1]$ is isometric to $L_{1}[0,1]$ and by the Alspach result [3] $\mathrm{Ces}_{1}[0,1]$ fails to have the WFPP.

Problem 2. Do Cesàro function spaces $\operatorname{Ces}_{p}(I)$ for $1<p<\infty$ have the weak fixed point property for nonexpansive mappings?

Let us state here also the following central problem in the fixed point theory.

Problem 3. Does reflexivity of a Banach space $X$ imply that $X \in F P P$ ?

On the other hand, the converse problem was solved by Pei-Kee Lin in 2008 by his surprising result: the space $l_{1}$ with the norm $\|x\|=\sup _{n \in \mathbb{N}} \frac{8^{n}}{1+8^{n}} \sum_{k=n}^{\infty}\left|x_{k}\right|$ is not reflexive but it has the fixed point property [59].

As the next consequence of Theorem 5.1, we mention the failure of the DunfordPettis property by spaces $\operatorname{Ces}_{p}(I), 1<p<\infty$. A Banach space $X$ has the DunfordPettis property if $x_{n} \rightarrow 0$ weakly in $X$ and $f_{n} \rightarrow 0$ weakly in the dual space $X^{*}$ imply $f_{n}\left(x_{n}\right) \rightarrow 0$. The classical examples of Banach spaces with the Dunford-Pettis property are AL-spaces and AM-spaces. Also, if the dual space $X^{*}$ has the Dunford-Pettis property then $X$ has itself this property. Of course, Cesàro sequence spaces $\operatorname{ces}_{p}, 1<p<\infty$, as reflexive spaces do not have the Dunford-Pettis property.

Corollary 5.3. If $1<p<\infty$, then $\operatorname{Ces}_{p}(I)$ do not have the Dunford-Pettis property.

Proof. By Theorem 5.1(c), $C e s_{p}(I)$ contains a complemented copy of $l_{p}$ and the space $l_{p}$ does not have the Dunford-Pettis property. On the other hand, if a Banach space $X$ has the Dunford-Pettis property, then any complemented subspace of $X$ should have also this property. Thus, $\operatorname{Ces}_{p}(I)$ do not have the Dunford-Pettis property.

Bennett [17] proved that the Cesàro sequence space $\operatorname{ces}_{p}, 1<p \leq \infty$, is not isomorphic to $l_{q}$-space for any $1 \leq q \leq \infty$. Analogous theorem is true also for Cesàro function spaces [8].

THEOREM 5.4. If $1<p \leq \infty$, then $\operatorname{Ces}_{p}(I)$ is not isomorphic to $L_{q}(I)$-space for any $1 \leq q \leq \infty$.

Proof. We will consider four cases:

$1^{\circ} q=1$. The spaces $\operatorname{Ces}_{p}(I)$ for $1<p<\infty$ are not isomorphic to $L_{1}(I)$ since $L_{1}(I)$ has the Dunford-Pettis property but $\operatorname{Ces}_{p}(I)$, as we have seen in Corollary 5.3, do not have this property. Clearly, $\mathrm{Ces}_{\infty}(I)$ as a non-separable space is not isomorphic to $L_{1}(I)$.

$2^{\circ} 1<q<\infty$. By Theorem 5.1(b), $C e s_{p}(I)$ contains an isomorphic copy of $L_{1}(I)$, thus it is not reflexive. Hence, it cannot be isomorphic to the reflexive space $L_{q}(I), 1<q<\infty$. 
$3^{\circ} q=\infty, 1<p<\infty$. The space $\operatorname{Ces}_{p}(I)$ is not isomorphic to $L_{\infty}(I)$ since the former space is separable and the latter one is non-separable.

$4^{\circ} p=q=\infty$. Since, by the Pełczyński theorem (cf. Albiac-Kalton 11, Theorem 4.3.10]), $L_{\infty}(I)$ is isomorphic to $\ell_{\infty}$, it is enough to show that $\operatorname{Ces}_{\infty}(I)$ is not isomorphic to $\ell_{\infty}$. By Theorem 5.1(b), $C e s_{\infty}(I)$ contains a complemented copy of a separable space while no separable subspace of $\ell_{\infty}$ is complemented in $\ell_{\infty}$. In fact, the latter space is prime, that is, every infinite dimensional complemented subspace of $\ell_{\infty}$ is isomorphic to $\ell_{\infty}$ (see Lindenstrauss-Tzafriri [60, Theorem 2.a.7] or Albiac-Kalton [1, Theorem 5.6.5]). Therefore, $\operatorname{Ces}_{\infty}(I)$ and $\ell_{\infty}$ are not isomorphic.

One of the most important problems related to investigation of the geometric structure of a Banach space $X$ is a description of the set of such $q$ that $X$ contains a (complemented) $l_{q}$-copy, that is, a (complemented) subspace isomorphic to the space $l_{q}, 1 \leq q \leq \infty$. In the case of $L_{p}$-spaces, the following result showing a difference of their geometric properties in the cases $1<p<2$ and $2<p<\infty$ (see [1, Theorem 6.4.19] and Kadec-Pełczyński classical paper [45]) holds:

Let $1 \leq q \leq \infty$. If $1 \leq p \leq 2$, then the space $l_{q}$ can be embedded isomorphically in $L_{p}[0,1]$ if and only if $p \leq q \leq 2$. If $2<p<\infty$, then the space $l_{q}$ can be embedded isomorphically in $L_{p}[0,1]$ if and only if $q=p$ or $q=2$.

A similar description of the set of all $q$ for which isomorphic copies of $l_{q}$ are contained in the Cesàro space $\operatorname{Ces}_{p}[0,1]$ was given in [8], Theorem 10.

\section{Theorem 5.5.}

(a) If $1 \leq p \leq 2$, then the space $l_{q}$ is embedded isomorphically into Ces $s_{p}[0,1]$ if and only if $1 \leq q \leq 2$.

(b) If $2<p<\infty$, then the space $l_{q}$ is embedded isomorphically into Ces $s_{p}[0,1]$ if and only if $1 \leq q \leq 2$ or $q=p$.

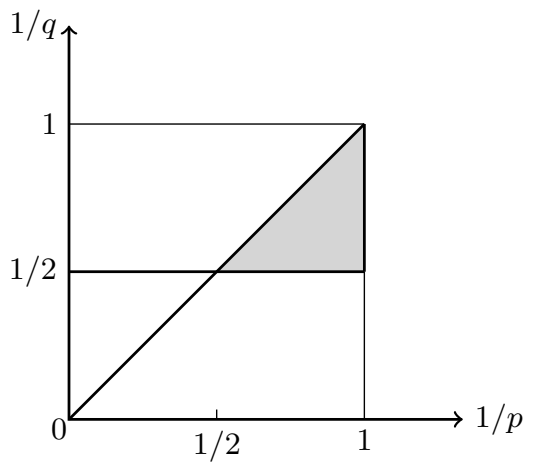

(a) $l_{q} \subseteq L_{p}$

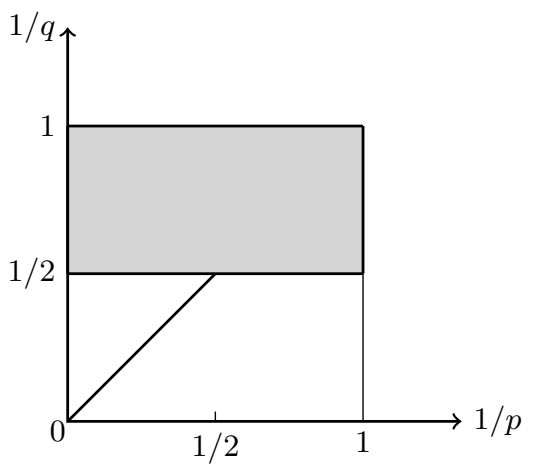

(b) $l_{q} \subseteq C e s_{p}$

Fig. $1-2 . l_{q}$ is embedded isomorphically into $L_{p}[0,1]$ and $C e s_{p}[0,1]$ 
A main reason of an essential difference between Theorem 5.5 and the preceding result for $L_{p}$-spaces consists in the fact that, in contrast to $L_{p}, 1<p<\infty$, the Cesàro space $\mathrm{Ces}_{p}[0,1]$ contains an isomorphic copy of $L_{1}[0,1]$ (see Theorem 5.1(b)).

In the final part of this section, we present the full description of complemented $l_{q}$-copies of the spaces $C e s_{p}[0,1]$. Firstly, recall the following classical result for $L_{p}$-spaces (see [1, Theorem 6.4.21] and again Kadec-Pełczyński paper [45]):

Let $1<p<\infty$. The space $L_{p}[0,1]$ contains a complemented subspace isomorphic to $l_{q}$ if and only if $q=p$ or $q=2$.

An analogous description of complemented $l_{q}$-copies in $C e s_{p}[0,1]$, which was given recently in [5] (see Theorem 2 and Corollary 1), again shows a substantial difference between the geometric properties of $L_{p}$-spaces and Cesàro function spaces.

THEOREM 5.6. Let $1 \leq p<\infty$ and $1 \leq q \leq \infty$. The following conditions are equivalent:

(a) The Cesàro space Ces $s_{p}[0,1]$ contains a complemented subspace $X \simeq l_{q}$.

(b) There is a sequence of disjoint functions $\left\{f_{n}\right\}_{n=1}^{\infty} \subset \operatorname{Ces}_{p}[0,1]$ such that $\left[f_{n}\right] \simeq l_{q}$.

(c) $q=1$ or $q=p$.

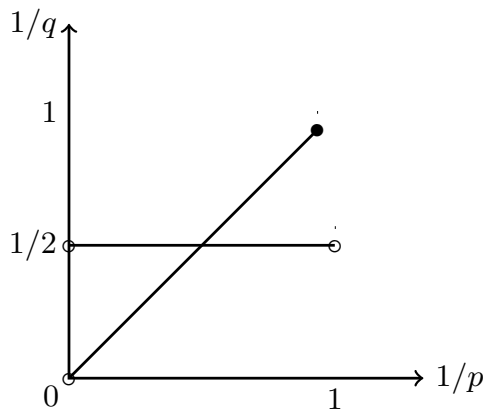

(c) $l_{q} \stackrel{c}{\subseteq} L_{p}$

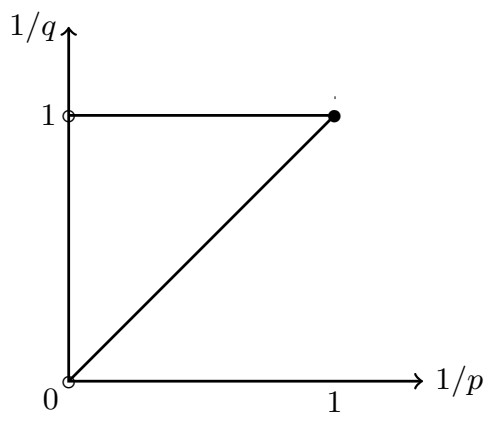

(d) $l_{q} \stackrel{c}{\subseteq} C e s_{p}$

Fig. 3-4. Complemented $l_{q}$-copies in $L_{p}[0,1]$ and $C e s_{p}[0,1]$

By Theorem 5.4. $\operatorname{Ces}_{p}(I), 1<p \leq \infty$, is not isomorphic to $L_{q}(I)$-space for any $1 \leq q \leq \infty$. From Theorem 5.6. combined with the fact that the space $L_{q}[0,1], 1<q<\infty$, contains a complemented subspace isomorphic to $l_{2}$, we obtain the following sharpening of Theorem 5.4 in the case $I=[0,1]$.

Corollary 5.7. Let $1<p<\infty$ and $p \neq 2$. Then the Cesàro space Ces $s_{p}[0,1]$ contains no complemented copy of the space $L_{q}[0,1]$ for any $1<q \leq \infty$.

REMARK 5.8. As it follows from Theorem 5.6, the space $\mathrm{Ces}_{2}[0,1]$ contains a complemented copy of $l_{2}$ and hence of $L_{2}[0,1]$. Moreover, by Theorem $5.1(\mathrm{~b})$, for any $1 \leq p \leq \infty$ the space $\operatorname{Ces}_{p}[0,1]$ contains a complemented copy of $L_{1}[0,1]$. Thus, the result of the last corollary does not hold if $p=2$ or $q=1$.

By Theorem 5.1(c), we saw that the space $\operatorname{Ces}_{p}[0,1], 1 \leq p<\infty$, contains a complemented $l_{p}$-copy. Moreover, it turns out that this space is in a sense "saturated" by 
complemented copies of $l_{p}$. Denote by $\mathcal{L}$ the vector space of all measurable on $[0,1]$ functions $x=x(t)$ such that $\int_{0}^{u}|x(t)| d t<\infty$ for any $0<u<1$. Define on $\mathcal{L}$ the topology $\tau$ generated by the following countable system of seminorms

$$
p_{n}(x):=\int_{0}^{1-1 / n}|x(t)| d t \quad(n=2,3, \ldots) .
$$

It is clear that for any $1 \leq p \leq \infty$ there is a continuous embedding $C e s_{p}[0,1] \hookrightarrow \mathcal{L}$.

The following result was proved also in [5].

THEOREM 5.9. Let $X$ be an arbitrary subspace of $\mathrm{Ces}_{p}[0,1](1 \leq p<\infty)$, which is not closed with respect to the topology $\tau$. Then $X$ contains a subspace $Y \simeq l^{p}$, complemented in $\mathrm{Ces}_{p}[0,1]$.

As is proved in [6] (see also [70]), an analogous result holds also in the case of general spaces whose norms are generated by positive sublinear operators and by $L_{p}$-norms.

6. Rademacher type and cotype of Cesàro spaces. Let $1 \leq p \leq \infty$. A Banach lattice $X$ is said to be $p$-convex (resp. $q$-concave) with a constant $K \geq 1$ if

$$
\left\|\left(\sum_{k=1}^{n}\left|x_{k}\right|^{p}\right)^{1 / p}\right\| \leq K\left(\sum_{k=1}^{n}\left\|x_{k}\right\|^{p}\right)^{1 / p} \quad\left(\operatorname{resp} . \quad\left(\sum_{k=1}^{n}\left\|x_{k}\right\|^{p}\right)^{1 / p} \leq K\left\|\left(\sum_{k=1}^{n}\left|x_{k}\right|^{p}\right)^{1 / p}\right\|\right)
$$

for every choice of vectors $x_{1}, x_{2}, \ldots, x_{n}$ in $X$ (with a natural modification if $p=\infty$ ). Of course, every Banach lattice is 1 -convex and $\infty$-concave with constant 1 . Moreover, the spaces $L_{p}(I)$ are $p$-convex and $p$-concave with constant 1 .

Let $r_{n}:[0,1] \rightarrow \mathbb{R}$, be the Rademacher functions, that is, $r_{n}(t)=\operatorname{sign}\left(\sin 2^{n} \pi t\right)$, $n \in \mathbb{N}$. A Banach space $X$ has type $1 \leq p \leq 2$ (resp. cotype $q \geq 2$ ) if there is a constant $K>0$ such that, for any choice of vectors $x_{1}, \ldots, x_{n}$ from $X$, we have

$$
\begin{gathered}
\int_{0}^{1}\left\|\sum_{k=1}^{n} r_{k}(t) x_{k}\right\| d t \leq K\left(\sum_{k=1}^{n}\left\|x_{k}\right\|^{p}\right)^{1 / p} \\
\left(\operatorname{resp.} \quad\left(\sum_{k=1}^{n}\left\|x_{k}\right\|^{q}\right)^{1 / q} \leq K \int_{0}^{1}\left\|\sum_{k=1}^{n} r_{k}(t) x_{k}\right\| d t\right)
\end{gathered}
$$

(with a natural modification in the case when $p=\infty$ or $q=\infty$ ). We say that a Banach space $X$ has trivial type or trivial cotype, if it does not have any type bigger than one or any finite cotype, respectively.

THEOREM 6.1. Let $I=[0,1]$ or $I=[0, \infty)$.

(a) If $1<p<\infty$, then the space $\operatorname{Ces}_{p}(I)$ is $p$-concave with constant 1 .

(b) If $1<p<\infty$, then the space $\operatorname{Ces}_{p}(I)$ has trivial type and cotype $\max (p, 2)$.

(c) The space $\mathrm{Ces}_{\infty}(\mathrm{I})$ has trivial type and trivial cotype.

Proof.

(a): The assertion can be proved by direct calculations (see also [8]).

(b): Since the space $\operatorname{Ces}_{p}(I), 1<p<\infty$, contains an isomorphic copy of $L_{1}(I)$ (see Theorem 5.1(b)), it has trivial type. On the other hand, by (a), the space $C e s_{p}(I)$ is $p$-concave, and therefore (see, for instance, [61, p. 100]) this space has cotype $\max (p, 2)$. 
Finally, it has no smaller cotype because of, by Theorem 5.1.(c), $\operatorname{Ces}_{p}(I)$ contains an isomorphic copy of $l_{p}$.

(c): The space $\operatorname{Ces}_{\infty}(I)$ has no absolutely continuous norm and, by the Lozanovskil theorem, it contains an isomorphic copy of $l_{\infty}$ (cf. [47. Chapter 10, $\S 4$, Theorem 4], [61, Proposition 1.a.7], [79, Theorem 3.8], [91, Theorem 4.1] and [92, Theorem 117.3]). Therefore, $\mathrm{Ces}_{\infty}(I)$ has trivial type and trivial cotype.

REMARK 6.2. The same proof shows that all assertions of the last theorem hold also for the Cesàro sequence spaces $c e s_{p}$.

7. Spaces $\operatorname{Ces}_{p}[0,1]$ and $\operatorname{Ces}_{p}[0, \infty)$ are isomorphic. Firstly, we present the construction of an isomorphism between the Cesàro function spaces $C e s_{p}[0, \infty)$ and $C e s_{p}[0,1]$ for $1<p<\infty$. Sy, Zhang and Lee proved that the norm in $\operatorname{Ces}_{p}[0, \infty)$ is equivalent to the following functional obtained by discretization:

$$
\|f\|_{0}=\left[\sum_{n=1}^{\infty}\left(\frac{1}{n} \sum_{k=1}^{n} s_{k}(f)\right)^{p}+\sum_{m=1}^{\infty}\left(m \sum_{k=m}^{\infty} t_{k}(f)\right)^{p} m^{-2}\right]^{1 / p}
$$

where

$$
s_{k}(f)=\int_{k}^{k+1}|f(s)| d s \quad \text { and } \quad t_{k}(f)=\int_{1 /(k+1)}^{1 / k}|f(s)| d s, \quad k=1,2, \ldots
$$

In [8], it was shown that an analogous assertion holds also for the spaces $C e s_{p}[0,1]$. Namely, letting

$$
b_{k}(f)=\int_{\alpha_{k}}^{\alpha_{k+1}}|f(t)| d t, \text { where } \alpha_{k}=\frac{1}{2}\left(2-k^{1-p}\right), \quad k=1,2, \ldots,
$$

we have

$$
\|f\|_{C(p)[0,1]} \approx\left[\sum_{n=1}^{\infty}\left(\frac{1}{n} \sum_{k=1}^{n} b_{k}(f)\right)^{p}+\sum_{m=2}^{\infty}\left(m \sum_{k=m}^{\infty} t_{k}(f)\right)^{p} m^{-2}\right]^{1 / p} .
$$

Denote by $k_{n}$ and $l_{m}(n, m=1,2, \ldots)$ one-to-one affine mappings such that

$$
k_{n}:[n, n+1] \rightarrow\left[\alpha_{n}, \alpha_{n+1}\right], \quad l_{m}:\left[\frac{1}{m+1}, \frac{1}{m}\right] \rightarrow\left[\frac{1}{m+2}, \frac{1}{m+1}\right]
$$

and define on the space $C e s_{p}[0,1]$ the linear operator $T$ by setting

$$
T f(x)=\sum_{n=1}^{\infty}\left(\alpha_{n+1}-\alpha_{n}\right) f\left(k_{n}(x)\right) \chi_{[n, n+1]}(x)+\sum_{m=1}^{\infty} f\left(l_{m}(x)\right) \chi_{[1 /(m+1), 1 / m]}(x) .
$$

By direct estimations, one can check that $T: \operatorname{Ces}_{p}[0,1] \rightarrow \operatorname{Ces}_{p}[0, \infty)$ is an isomorphism and we get the following result (see [8], Theorem 9).

THEOREM 7.1. If $1<p<\infty$, then the Cesàro function spaces $\operatorname{Ces}_{p}[0,1]$ and $\operatorname{Ces}_{p}[0, \infty)$ are isomorphic.

In the case $p=\infty$ we are able to prove even a stronger result (see also [8]).

THEOREM 7.2. If $1 \leq p<\infty$, then the $p$-convexifications $\operatorname{Ces}_{\infty}^{(p)}[0,1]$ and $C e s_{\infty}^{(p)}[0, \infty)$ of Cesàro function spaces on $[0,1]$ and $(0, \infty)$ are isomorphic. In particular, the spaces $\mathrm{Ces}_{\infty}[0,1]$ and $\mathrm{Ces}_{\infty}[0, \infty)$ are isomorphic. 
Proof. It is not difficult to check that

$$
\|f\|_{C(\infty)^{(p)}[0, \infty)} \approx \sup _{k \in \mathbb{Z}}\left(2^{-k+1} \int_{2^{k-1}}^{2^{k}}|f(t)|^{p} d t\right)^{1 / p}
$$

and

$$
\|f\|_{C(\infty)^{(p)}[0,1]} \approx \sup _{k=0,-1,-2, \ldots}\left(2^{-k+1} \int_{2^{k-1}}^{2^{k}}|f(t)|^{p} d t\right)^{1 / p} .
$$

Moreover, for every $k \in \mathbb{Z}$

$$
2^{-k+1} \int_{2^{k-1}}^{2^{k}}|f(t)|^{p} d t=\int_{0}^{1}\left|f\left(2^{k-1}(t+1)\right)\right|^{p} d t .
$$

Let us define the linear transforms

$$
T_{1}: \operatorname{Ces}_{\infty}^{(p)}[0, \infty) \rightarrow l_{\infty}\left(\sum_{k=-\infty}^{\infty} \oplus L_{p}[0,1]\right), \quad T_{1} f=\left(f\left(2^{k-1}(t+1)\right)\right)_{k \in \mathbb{Z}}
$$

and

$$
T_{2}: \operatorname{Ces}_{\infty}^{(p)}[0,1] \rightarrow l_{\infty}\left(\sum_{k=0}^{-\infty} \oplus L_{p}[0,1]\right), \quad T_{2} f=\left(f\left(2^{k-1}(t+1)\right)\right)_{k=0}^{-\infty} .
$$

The preceding formulas show that $T_{1}$ and $T_{2}$ are isomorphisms. Moreover, it is clear that the spaces $l_{\infty}\left(\sum_{k=-\infty}^{\infty} \oplus L_{p}[0,1]\right)$ and $l_{\infty}\left(\sum_{k=0}^{-\infty} \oplus L_{p}[0,1]\right)$ are isomorphic. Therefore, the spaces $C e s_{\infty}^{(p)}[0, \infty)$ and $C e s_{\infty}^{(p)}[0,1]$ are isomorphic as well.

Problem 4. Is the Cesàro function space Ces ${ }_{\infty}[0,1]$ isomorphic to the Cesàro sequence space ces $_{\infty}$ ?

Note that a well-known Pełczyński theorem (1958) states that $L_{\infty}[0,1]$ is isomorphic to $l_{\infty}$.

8. Rademacher functions in Cesàro spaces. Recall that the Rademacher functions $r_{n}:[0,1] \rightarrow \mathbb{R}$ are defined by the formula $r_{n}(t)=\operatorname{sign}\left(\sin 2^{n} \pi t\right)(n \in \mathbb{N})$. From the classical Khintchine inequality it follows that these functions span an isomorphic copy of $l_{2}$ in $L_{p}$ for every $0<p<\infty$. Investigations of Rademacher sums in general rearrangement invariant spaces rather than $L_{p}$ are well presented in a series of papers and in the books by Lindenstrauss-Tzafriri [61], Krein-Petunin-Semenov [53] and Astashkin [4]. However, not so much we know on the behaviour of the Rademacher functions in general Banach lattices.

In this section we consider the Rademacher functions in the spaces $\operatorname{Ces}_{p}[0,1]$. The first result proved in [9] Theorems 1 and 6] is related to the case $1 \leq p<\infty$.

THEOREM 8.1. For any $1 \leq p<\infty$ the Rademacher functions $\left\{r_{n}\right\}$ span an isomorphic copy of $l_{2}$ in $\mathrm{Ces}_{p}[0,1]$. Moreover, the subspace $\left[r_{n}\right]$ is not complemented in Ces ${ }_{p}[0,1]$.

Proof. To prove the first assertion of the theorem, we have to show that there are positive constants $A_{p}>0$ and $B_{p}>0$ such that

$$
A_{p}\left(\sum_{k=1}^{n} a_{k}^{2}\right)^{1 / 2} \leq\left\|\sum_{k=1}^{n} a_{k} r_{k}\right\|_{C(p)} \leq B_{p}\left(\sum_{k=1}^{n} a_{k}^{2}\right)^{1 / 2}
$$


for any real numbers $a_{1}, a_{2}, \ldots, a_{n}$ and any $n \in \mathbb{N}$. It can be done by comparing the norms of the Cesàro spaces and $L_{p}$-spaces and by using the classical Khintchine inequality in $L_{p}[0,1]$ for $0<p<\infty$. In fact, it is sufficient to check that the following chain of embeddings holds:

$$
L_{p} \stackrel{p^{\prime}}{\hookrightarrow} C e s_{p} \stackrel{1}{\hookrightarrow} C e s_{1}=L_{1}(\ln 1 / t) \stackrel{C}{\hookrightarrow} L_{1 / 3} \text { if } 1<p<\infty
$$

with some constant $C>0$. The first two embeddings are immediate consequences of Theorem 3.1(c) and (e). To prove the last one, assume that $f \in L_{1}(\ln 1 / t)$ with $\|f\|_{L_{1}(\ln 1 / t)}=1$. Since $\ln 1 / t \geq 1-t$ for $0<t \leq 1$ and the function $1-t$ decreases, we have

$$
\begin{aligned}
1 & =\int_{0}^{1}|f(t)| \ln 1 / t d t \geq \int_{0}^{1}|f(t)|(1-t) d t \geq \int_{0}^{1} f^{*}(1-t)(1-t) d t \\
& =\int_{0}^{1} f^{*}(s) s d s \geq \int_{0}^{t} f^{*}(s) s d s \geq f^{*}(t) t^{2} / 2
\end{aligned}
$$

or $f^{*}(t) \leq 2 t^{-2}$. Thus,

$$
\int_{0}^{1}|f(t)|^{1 / 3} d t=\int_{0}^{1} f^{*}(t)^{1 / 3} d t \leq \int_{0}^{1}\left(2 t^{-2}\right)^{1 / 3} d t=3 \cdot 2^{1 / 3}
$$

and so $\|f\|_{L_{1 / 3}} \leq 54$, which finishes the proof of the last embedding with $C=54$, and the result follows.

The proof of the second assertion of the theorem is based on the fact that the space $C e s_{p}[0,1]$ contains an isomorphic copy of $L_{1}[0,1]$ (for a detailed proof see [9]).

The behaviour of Rademacher functions in the space $C e s_{\infty}[0,1]$ is much more interesting. In the following theorem (see [9, Theorem 2]), as above, $K^{(p)}:=K^{(p)}[0,1]$ is $p$-convexification of the space $K:=\operatorname{Ces}_{\infty}[0,1]$.

THEOREM 8.2. For any $1 \leq p<\infty$ we have the equivalence

$$
\left\|\sum_{k=1}^{n} a_{k} r_{k}\right\|_{K^{(p)}} \approx\left\|\left\{a_{k}\right\}_{k=1}^{n}\right\|_{l_{2}}+\max _{1 \leq m \leq n}\left|\sum_{k=1}^{m} a_{k}\right|, \quad n=1,2, \ldots,
$$

with a constant which depends only on $p$.

REMARK 8.3. From 10 we obtain

$$
\left\|\sum_{k=1}^{\infty} a_{k} r_{k}\right\|_{K^{(p)}} \approx\left\|\left\{a_{k}\right\}_{k=1}^{\infty}\right\|_{l_{2}}+\sup _{m \in \mathbb{N}}\left|\sum_{k=1}^{m} a_{k}\right|,
$$

and hence the series $\sum_{k=1}^{\infty} a_{k} r_{k}$ is convergent in $K^{(p)}$ if and only if both series $\sum_{k=1}^{\infty} a_{k}^{2}$ and $\sum_{k=1}^{\infty} a_{k}$ are convergent.

Recall that $r_{n} \stackrel{w}{\rightarrow} 0$ in an rearrangement invariant space $X$ on $[0,1]$ whenever $X$ is not equal to $L_{\infty}[0,1]$ up to an equivalent norm (cf. [77], see also [61, Proposition 2.c.10]). THEOREM 8.4. If $1 \leq p<\infty$, then $r_{n} \stackrel{w}{\rightarrow} 0$ in $C e s_{p}[0,1]$, and therefore the lattice operations in this space are not weakly sequentially continuous. 
Proof. Taking into account that the Rademacher functions form an orthonormal sequence, from Bessel's inequality we obtain

$$
\lim _{n \rightarrow \infty} \int_{0}^{1} f(t) r_{n}(t) d t=0
$$

for every $f \in L_{2}[0,1]$. Since the sequence $\left\{r_{n}\right\}$ is uniformly bounded and $L_{2}$ is dense in $L_{1}$, we conclude that the latter equality holds for all $f \in L_{1}$. From the embedding $L_{p} \subset C e s_{p}$ we infer $\left(C e s_{p}\right)^{\star} \subset\left(L_{p}\right)^{\star}=L_{p^{\prime}} \subset L_{1}$ and therefore we obtain the weak convergence of Rademacher functions to zero in $\mathrm{Ces}_{p}[0,1]$. In particular, the lattice operations in $C e s_{p}[0,1]$ are not weakly sequentially continuous since $r_{n} \stackrel{w}{\rightarrow} 0$ in $C e s_{p}[0,1]$ but $\left|r_{n}\right|=1$ for all $n \in \mathbb{N}$.

Problem 5. Are the lattice operations weakly sequentially continuous in the space $K^{(p)}[0,1], 1 \leq p<\infty$ ?

The last result of this section is proved also in [9].

THEOREM 8.5. The subspace $\left[r_{n}\right]$ generated by the Rademacher functions in the Cesàro space $\mathrm{Ces}_{\infty}[0,1]$ is not complemented in this space.

Problem 6. Clarify if the subspace $\left[r_{n}\right]$ generated by the Rademacher functions in $K^{(p)}$ for $1<p<\infty$ is complemented or not in this space.

9. On weak Banach-Saks property of $\boldsymbol{C e s}_{p}[\mathbf{0 , 1}]$. Let us recall that a Banach space $X$ is said to have the weak Banach-Saks property if every weakly null sequence $\left\{x_{n}\right\}_{n=1}^{\infty} \subset X$ contains a subsequence $\left\{x_{n_{k}}\right\}$ whose first arithmetical means converge strongly to zero, that is, $\lim _{m \rightarrow \infty} \frac{1}{m}\left\|\sum_{k=1}^{m} x_{n_{k}}\right\|_{X}=0$.

It is known that uniformly convex spaces, $c_{0}, l_{1}$ and $L_{1}$ have the weak Banach-Saks property, but $C[0,1]$ and $l_{\infty}$ do not have. We should mention that the result on $L_{1}$-space, proved by Szlenk in 1965, was a very important break-through in investigation of the weak Banach-Saks property.

In 1982 Rakov proved that a Banach space with non-trivial type has the weak BanachSaks property. Recently, Dodds-Semenov-Sukochev (2004) examined the weak BanachSaks property in the class of rearrangement invariant spaces and Astashkin-Sukochev (2007) completely characterized Marcinkiewicz spaces having this property.

The spaces $C e s_{p}[0,1]$ for $1 \leq p<\infty$ neither have non-trivial type nor rearrangement invariant. Nevertheless, the following result, which was proved in [8], holds.

TheOrem 9.1. If $1 \leq p<\infty$, then the Cesàro function space Ces $s_{p}[0,1]$ has the weak Banach-Saks property.

The proof of this theorem given in [8] is based on two main ingredients: an application of the Szlenk result and the following characterization of weakly null sequences in $\mathrm{Ces}_{p}[0,1], 1<p<\infty$. 
Theorem 9.2. Let $1<p<\infty$ and let $\left\{x_{n}\right\}_{n=1}^{\infty} \subset C e s_{p}[0,1]$. Then $x_{n} \stackrel{w}{\rightarrow} 0$ in $C e s_{p}[0,1]$ if and only if

(a) there exists a constant $M>0$ such that $\left\|x_{n}\right\|_{C(p)} \leq M$ for all $n=1,2, \ldots$;

(b) for every set $A \subset[0,1]$ such that $A \subset[h, 1-h]$ for some $h \in(0,1 / 2)$ we have $\int_{A} x_{n}(t) d t \rightarrow 0$ as $n \rightarrow \infty$.

Recently, in [12], we have presented another much shorter proof of Theorem 9.1 by observing that $\operatorname{Ces}_{p}[0,1]$ is a closed subspace of the mixed norm space $L_{p}\left[L_{1}\right]$. Since the latter space is equal to the Bochner vector-valued space $L_{p}\left(L_{1}\right)$ (see [39, Theorem 1.1] and [22, Theorem 2.2]), from the Cembranos result [23, Theorem C] (see also [58, pp. 295-302]) and the Komlós theorem [51] it follows that the space $L_{p}\left[L_{1}\right]$ has the weak Banach-Saks property. Hence, as a closed subspace of $L_{p}\left[L_{1}\right]$, the space $C e s_{p}[0,1]$ also possesses this property.

10. Interpolation of Cesàro and Copson spaces. For more detailed definitions of a Banach couple, intermediate and interpolation spaces with some results introduced briefly below, see [19] and [18, pp. 95-116].

For a Banach couple $\bar{X}=\left(X_{0}, X_{1}\right)$ of two compatible Banach spaces $X_{0}$ and $X_{1}$ consider two Banach spaces $X_{0} \cap X_{1}$ and $X_{0}+X_{1}$ with their natural norms

$$
\|f\|_{X_{0} \cap X_{1}}=\max \left(\|f\|_{X_{0}},\|f\|_{X_{1}}\right), \quad \text { for } \quad f \in X_{0} \cap X_{1} \text {, }
$$

and

$\|f\|_{X_{0}+X_{1}}=\inf \left\{\left\|f_{0}\right\|_{X_{0}}+\left\|f_{1}\right\|_{X_{1}}: f=f_{0}+f_{1}, f_{0} \in X_{0}, f_{1} \in X_{1}\right\}, \quad$ for $\quad f \in X_{0}+X_{1}$.

A Banach space $X$ is called an intermediate space between $X_{0}$ and $X_{1}$ if $X_{0} \cap X_{1} \hookrightarrow$ $X \hookrightarrow X_{0}+X_{1}$. Such a space $X$ is called an interpolation space between $X_{0}$ and $X_{1}$ if, for any bounded linear operator $T: X_{0}+X_{1} \rightarrow X_{0}+X_{1}$ such that the restriction $T_{\mid X_{i}}: X_{i} \rightarrow X_{i}$ is bounded for $i=0,1$, the restriction $T_{\left.\right|_{X}}: X \rightarrow X$ is also bounded and $\|T\|_{X \rightarrow X} \leq C \max \left\{\|T\|_{X_{0} \rightarrow X_{0}},\|T\|_{X_{1} \rightarrow X_{1}}\right\}$ for some $C \geq 1$. If $C=1$, then $X$ is called an exact interpolation space between $X_{0}$ and $X_{1}$.

One of the most important interpolation methods is the $K$-method known also as the real Lions-Peetre interpolation method. For a Banach couple $\bar{X}=\left(X_{0}, X_{1}\right)$ the Peetre $K$-functional of an element $f \in X_{0}+X_{1}$ is defined for $t>0$ by

$$
K\left(t, f ; X_{0}, X_{1}\right)=\inf \left\{\left\|f_{0}\right\|_{X_{0}}+t\left\|f_{1}\right\|_{X_{1}}: f=f_{0}+f_{1}, f_{0} \in X_{0}, f_{1} \in X_{1}\right\} .
$$

Then the spaces of the K-method of interpolation are

$$
\left(X_{0}, X_{1}\right)_{\theta, p}=\left\{f \in X_{0}+X_{1}:\|f\|_{\theta, p}=\left(\int_{0}^{\infty}\left[t^{-\theta} K\left(t, f ; X_{0}, X_{1}\right)\right]^{p} \frac{d t}{t}\right)^{1 / p}<\infty\right\}
$$

if $0<\theta<1$ and $1 \leq p<\infty$, and

$$
\left(X_{0}, X_{1}\right)_{\theta, \infty}=\left\{f \in X_{0}+X_{1}:\|f\|_{\theta, \infty}=\sup _{t>0} K\left(t, f ; X_{0}, X_{1}\right) t^{-\theta}<\infty\right\}
$$

if $0 \leq \theta \leq 1$. It is not hard to check that $\left(X_{0}, X_{1}\right)_{\theta, p}$ is an exact interpolation space between $X_{0}$ and $X_{1}$ for arbitrary $0<\theta<1$ and $1 \leq p \leq \infty$.

Very useful in calculations are the so-called reiteration formulae showing the stability of the $K$-method of interpolation. If $1 \leq p_{0}, p_{1}, p \leq \infty, 0<\theta_{0}, \theta_{1}, \theta<1$ and $\theta_{0} \neq \theta_{1}$, 
then

$$
\left(\left(X_{0}, X_{1}\right)_{\theta_{0}, p_{0}},\left(X_{0}, X_{1}\right)_{\theta_{1}, p_{1}}\right)_{\theta, p}=\left(X_{0}, X_{1}\right)_{(1-\theta) \theta_{0}+\theta \theta_{1}, p}
$$

with equivalent norms (see [18, Theorem 2.4, p. 311] or [19, Theorems 3.5.3] or [89, Theorem 1.10.2]) and in the extreme cases

$$
\begin{gathered}
\left(X_{0},\left(X_{0}, X_{1}\right)_{\theta_{1}, p_{1}}\right)_{\theta, p}=\left(X_{0}, X_{1}\right)_{\theta \theta_{1}, p}, \\
\left(\left(X_{0}, X_{1}\right)_{\theta_{0}, p_{0}}, X_{1}\right)_{\theta, p}=\left(X_{0}, X_{1}\right)_{(1-\theta) \theta_{0}+\theta, p}
\end{gathered}
$$

with equivalent norms (see [43], formulae 3.16 and 3.17).

We present here the interpolation results for Cesàro and Copson spaces from [11] and [13. It should be noted that interpolation properties of Cesàro spaces are more non-trivial and interesting than those of Copson spaces.

TheOREM 10.1. Let $I=[0,1]$ or $[0, \infty)$.

(a) If $1 \leq p_{0}<p_{1} \leq \infty$ and $\frac{1}{p}=\frac{1-\theta}{p_{0}}+\frac{\theta}{p_{1}}$ with $0<\theta<1$, then

$$
\left(\operatorname{cop}_{p_{0}}, \operatorname{cop}_{p_{1}}\right)_{\theta, p}=\operatorname{cop}_{p} \quad \text { and } \quad\left(\operatorname{Cop}_{p_{0}}(I), \operatorname{Cop}_{p_{1}}(I)\right)_{\theta, p}=\operatorname{Cop}_{p}(I) \text {. }
$$

(b) If $1<p_{0}<p_{1} \leq \infty$ and $\frac{1}{p}=\frac{1-\theta}{p_{0}}+\frac{\theta}{p_{1}}$ with $0<\theta<1$, then

$$
\left(\operatorname{ces}_{p_{0}}, \operatorname{ces}_{p_{1}}\right)_{\theta, p}=\operatorname{ces}_{p} \quad \text { and } \quad\left(\operatorname{Ces}_{p_{0}}(I), \operatorname{Ces}_{p_{1}}(I)\right)_{\theta, p}=\operatorname{Ces}_{p}(I) .
$$

Proof. (a): In the case of sequence spaces the proof follows from the identification

$$
\left(l_{1}, l_{1}(1 / k)\right)_{1-1 / p, p}=\operatorname{cop}_{p}, \quad 1<p<\infty
$$

(see [11, Theorem 1 (i)]), from the equalities $l_{1}=\operatorname{cop}_{1}, l_{1}(1 / k)=\operatorname{cop}_{\infty}$ and from reiteration formulae (11), 12). The proof is completely similar for Copson function spaces, only we use the following identification of them as interpolation spaces with respect to a couple of weighted $L_{1}$-spaces [11, Theorem 1 (ii) and (iii)]:

$$
\left(L_{1}(I), L_{1}(1 / t)(I)\right)_{1-1 / p, p}=\operatorname{Cop}_{p}(I), \quad 1<p<\infty,
$$

and the equalities $\operatorname{Cop}_{\infty}(I)=L_{1}(1 / t)(I), \operatorname{Cop}_{1}(I)=L_{1}(I)$.

(b): In the case of sequence and function spaces on $[0, \infty)$, provided that $p_{1}<\infty$, it is sufficient to apply equalities $(13)$ from the part (a) and Theorem 3.2 (a). If $p_{1}=\infty$, equalities (14) are proved in [12] (see Theorem 2) and [11] (see Corollary 2).

In contrast to the case $[0, \infty)$, the space $\operatorname{Ces}_{p}[0,1], 1 \leq p<\infty$, is not an intermediate space between $L_{1}[0,1]$ and $C e s_{\infty}[0,1]$. However, we have

$$
\operatorname{Ces}_{\infty}[0,1] \stackrel{1}{\hookrightarrow} \operatorname{Ces}_{p}[0,1] \stackrel{1}{\hookrightarrow} \operatorname{Ces}_{1}[0,1]=L_{1}(\ln 1 / t)[0,1] \stackrel{1}{\hookrightarrow} L_{1}(1-t)[0,1] .
$$

Moreover, as was shown in [11, Theorem 2], if $1<p<\infty$, the following equality holds:

$$
\left(L_{1}(1-t)[0,1], \operatorname{Ces}_{\infty}[0,1]\right)_{1-1 / p, p}=\operatorname{Ces}_{p}[0,1] .
$$

Therefore, if $I=[0,1]$, the second equality in $(14)$ can be proved in the same way as in the part (a) by using reiteration formulae (11) and 12 .

REMARK 10.2. The space $\operatorname{ces}_{p}$ for $1<p<\infty$ can be obtained also as an interpolation space with respect to the couple $\left(l_{1}, l_{1}\left(2^{-n}\right)\right)$ by the so-called $K^{+}$-method being a version of the standard K-method, precisely, ces $s_{p}=\left(l_{1}, l_{1}\left(2^{-n}\right)\right)_{l_{p}(1 / n)}^{K^{+}}$(cf. [25, the proof of Theorem 6.4]). However, by now, for the $K^{+}$-method there is no suitable reiteration theorem. 
REMARK 10.3. Note that the proof of the second equality in (14) for the spaces on $I=[0, \infty)$ in [11] is essentially based on some results from the paper [71]. Moreover, another proof of this equality in the case $I=[0, \infty)$ was also given by Sinnamon [83, Corollary 2].

REMARK 10.4. As was mentioned in Section 4, the restriction of the space $C e s_{p}[0, \infty)$, $1<p<\infty$, to the interval $[0,1]$ coincides with the intersection $\operatorname{Ces}_{p}[0,1] \cap L_{1}[0,1]$. Therefore, if we "restrict" the second formula in (14) for $[0, \infty)$ to $[0,1]$ we obtain

$$
\left(\operatorname{Ces}_{p_{0}}[0,1] \cap L_{1}[0,1], \operatorname{Ces}_{p_{1}}[0,1] \cap L_{1}[0,1]\right)_{\theta, p}=\operatorname{Ces}_{p}[0,1] \cap L_{1}[0,1],
$$

where $1<p_{0}<p_{1}<\infty$ and $\frac{1}{p}=\frac{1-\theta}{p_{0}}+\frac{\theta}{p_{1}}$. The latter equality shows that the real method $(\cdot, \cdot)_{\theta, p}$ "properly" interpolates the intersections of Cesàro spaces on the segment $[0,1]$ with the space $L_{1}[0,1]$ or, more precisely, we have

$$
\left(\operatorname{Ces}_{p_{0}}[0,1] \cap L_{1}[0,1], \operatorname{Ces}_{p_{1}}[0,1] \cap L_{1}[0,1]\right)_{\theta, p}=\left(\operatorname{Ces}_{p_{0}}[0,1], C_{e s_{p_{1}}}[0,1]\right)_{\theta, p} \cap L_{1}[0,1],
$$

for all $1<p_{0}<p_{1} \leq \infty, 0<\theta<1$ and $\frac{1}{p}=\frac{1-\theta}{p_{0}}+\frac{\theta}{p_{1}}$.

Recalling that $\operatorname{Ces}_{1}[0,1]=L_{1}(\ln 1 / t)$, let us consider a problem if $\operatorname{Ces}_{p}[0,1]$, $1<p<\infty$, is an interpolation space between $\operatorname{Ces}_{1}[0,1]$ and $\operatorname{Ces}_{\infty}[0,1]$. We show that for arbitrary $1<p<\infty$ the following embedding holds:

$$
\left(\operatorname{Ces}_{1}[0,1], \operatorname{Ces}_{\infty}[0,1]\right)_{1-1 / p, p} \stackrel{1}{\hookrightarrow} \operatorname{Ces}_{p}[0,1] .
$$

First, for any $f \in C e s_{1}$ and all $0<t \leq 1$ we have

$$
K(t, f):=K\left(t, f ; \text { Ces }_{1}, C e s_{\infty}\right) \geq \int_{0}^{t}(C f)^{*}(s) d s .
$$

In fact, we can assume that $f \geq 0$. If $f=g+h, g \geq 0, h \geq 0, g \in C e s_{1}, h \in C e s_{\infty}$, then $C f=C g+C h$ and, therefore, by using the well-known formula for K-functional with respect to the couple $\left(L_{1}, L_{\infty}\right)$ (cf. [18, Theorem 5.1.6]), we obtain

$$
\begin{aligned}
\|g\|_{C(1)}+t\|h\|_{C(\infty)} & =\|C g\|_{L_{1}}+t\|C h\|_{L_{\infty}} \\
& \geq \inf \left\{\|y\|_{L_{1}}+t\|z\|_{L_{\infty}}: C f=y+z, y \in L_{1}, z \in L_{\infty}\right\} \\
& =K\left(t, C f ; L_{1}, L_{\infty}\right)=\int_{0}^{t}(C f)^{*}(s) d s .
\end{aligned}
$$

Taking the infimum over all suitable $g$ and $h$ we get 17 . Next, by the definition of the real interpolation spaces, we obtain

$$
\begin{aligned}
\|f\|_{1-1 / p, p}^{p} & \geq \int_{0}^{1}\left[t^{1 / p-1} K(t, f)\right]^{p} \frac{d t}{t}=\int_{0}^{1} t^{-p} K(t, f)^{p} d t \\
& \geq \int_{0}^{1} t^{-p}\left[\int_{0}^{t}(C f)^{*}(s) d s\right]^{p} d t \geq\|C f\|_{L_{p}}^{p}=\|f\|_{C(p)}^{p},
\end{aligned}
$$

and the proof of the embedding 16 is complete.

However, the opposite embedding does not hold. Moreover, in [11, Theorem 6] the following result is proved.

THEOREM 10.5. For any $1<p<\infty$ the space $\operatorname{Ces}_{p}[0,1]$ is not an interpolation space between the spaces $\mathrm{Ces}_{1}[0,1]$ and $\mathrm{Ces}_{\infty}[0,1]$. 
REMARK 10.6. Equality 15 and the last theorem show that the weighted space $L_{1}(1-t)[0,1]$ is in a sense the "proper" end of the scale of Cesàro spaces $\operatorname{Ces}_{p}[0,1]$, $1<p \leq \infty$.

Problem 7. The proof of Theorem 10.5 given in [11] is of functorial "flavour". Hence, it would be worth to construct a sequence of operators $\left\{T_{n}\right\}_{n=1}^{\infty}$ which are uniformly bounded in $\operatorname{Ces}_{1}[0,1]$ and $\operatorname{Ces}_{\infty}[0,1]$ but $\sup _{n=1,2, \ldots}\left\|T_{n}\right\|_{\operatorname{Ces}_{p}[0,1] \rightarrow \operatorname{Ces}_{p}[0,1]}=\infty$ for any $1<p<\infty$.

After the negative answer given in Theorem 10.5 it is interesting to find a space which we get by the K-method applied to the couple $\left(\operatorname{Ces}_{1}[0,1], \operatorname{Ces}_{\infty}[0,1]\right)$. A rather elaborate estimations in [11, Theorems 3 and 5] give the following result with an identification of the latter space.

TheOREM 10.7. For every $1<p<\infty$ we have

$$
\left(\operatorname{Ces}_{1}[0,1], \operatorname{Ces}_{\infty}[0,1]\right)_{1-1 / p, p}=\operatorname{Ces}_{p}(\ln e / t)[0,1],
$$

where the weighted Cesàro function space $\operatorname{Ces}_{p}\left(\ln \frac{e}{t}\right)[0,1]$ is a Banach space generated by the norm

$$
\|f\|_{C(p, \ln )}:=\left(\int_{0}^{1}\left(\frac{1}{x} \int_{0}^{x}|f(t)| d t\right)^{p} \ln \frac{e}{x} d x\right)^{1 / p} .
$$

The crucial point in proving Theorem 10.7 is the following description of the $\mathrm{K}$-functional for the couple $\left(\operatorname{Ces}_{1}[0,1], \operatorname{Ces}_{\infty}[0,1]\right)$ : for every $f \in \operatorname{Ces}_{1}[0,1]$ and for all $0<t \leq 1$ we have

$$
K\left(t, f ; \operatorname{Ces}_{1}[0,1], \operatorname{Ces}_{\infty}[0,1]\right) \approx\left\|f \chi_{\left[0, \tau_{1}(t)\right] \cup\left[\tau_{2}(t), 1\right]}\right\|_{C(1)}+t\left\|f \chi_{\left[\tau_{1}(t), \tau_{2}(t)\right]}\right\|_{C(\infty)},
$$

where $\tau_{1}(t)=t / \ln (e / t)$ and $\tau_{2}(t)=e^{-t}$ (cf. [11, Theorem 3]). Clearly, if $t \geq 1$, we have $K\left(t, f ; \operatorname{Ces}_{1}[0,1], \operatorname{Ces}_{\infty}[0,1]\right)=\|f\|_{C(1)}$.

Note that $C e s_{p}\left(\ln \frac{e}{t}\right)[0,1] \stackrel{1}{\hookrightarrow} \operatorname{Ces}_{p}[0,1]$ for every $1<p<\infty$, and this embedding is strict.

\section{References}

[1] F. Albiac, N. J. Kalton, Topics in Banach Space Theory, Grad. Texts in Math. 233, Springer, New York 2006.

[2] C. D. Aliprantis, O. Burkinshaw, Positive Operators, Academic Press, Orlando 1985.

[3] D. E. Alspach, A fixed point free nonexpansive map, Proc. Amer. Math. Soc. 82 (1981), 423-424.

[4] S. V. Astashkin, Rademacher functions in symmetric spaces, Sovrem. Mat. Fundam. Napravl. 32 (2009), 3-161 (Russian); English transl.: J. Math. Sci. (New York) 169 (2010), 725-886.

[5] S. V. Astashkin, On the geometric properties of Cesàro spaces, Mat. Sb. 203 (2012), no. 4, 61-80; English transl.: Sb. Math. 203 (2012), 514-533.

[6] S. V. Astashkin, Geometrical properties of Banach spaces generated by sublinear operators, Positivity 17 (2013), 223-234. 
[7] S. V. Astashkin, L. Maligranda, Cesàro function spaces fail the fixed point property, Proc. Amer. Math. Soc. 136 (2008), 4289-4294.

[8] S. V. Astashkin, L. Maligranda, Structure of Cesàro function spaces, Indag. Math. (N.S.) 20 (2009), 329-379.

[9] S. V. Astashkin, L. Maligranda, Rademacher functions in Cesàro type spaces, Studia Math. 198 (2010), 235-247.

[10] S. V. Astashkin, L. Maligranda, Geometry of Cesàro function spaces, Funktsional. Anal. i Prilozhen. 45 (2011), no. 1, 79-83; English transl.: Funct. Anal. Appl. 45 (2011), 64-68.

[11] S. V. Astashkin, L. Maligranda, Interpolation of Cesàro sequence and function spaces, Studia Math. 215 (2013), 39-69.

[12] S. V. Astashkin, L. Maligranda, A short proof of some recent results related to Cesàro function spaces, Indag. Math. (N.S.) 24 (2013), 589-592.

[13] S. V. Astashkin, L. Maligranda, Interpolation of Cesàro and Copson spaces, in: Banach and Function Spaces IV (Kitakyushu, 2012), Yokohama Publ., Yokohama 2014, 123-133.

[14] S. V. Astashkin, F. A. Sukochev, Banach-Saks property in Marcinkiewicz spaces, J. Math. Anal. Appl. 336 (2007), 1231-1258.

[15] S. Banach, Théorie des Opérations Linéaires, Monografie Matematyczne 1, PWN, Warsaw 1932; Reprinted in: Stefan Banach, Euvres, Vol. II, PWN, Warszawa 1979, 13-219; English transl.: Theory of Linear Operations, North-Holland Math. Library 38, NorthHolland, Amsterdam 1987.

[16] M. S. Baouendi, C. Goulaouic, Commutation de l'intersection et des foncteurs d'interpolation, C. R. Acad. Sci. Paris Sér. A-B 265 (1967), A313-A315.

[17] G. Bennett, Factorizing the Classical Inequalities, Mem. Amer. Math. Soc. 120 (1996), no. 576 .

[18] C. Bennett, R. Sharpley, Interpolation of Operators, Pure Appl. Math. 129, Academic Press, Boston, 1988.

[19] J. Bergh, J. Löfström, Interpolation Spaces. An Introduction, Grundlehren Math. Wiss. 223, Springer, Berlin 1976.

[20] C. Bessaga, A. Pełczyński, On extreme points in separable conjugate spaces, Israel J. Math. 4 (1966), 262-264.

[21] Yu. A. Brudnyı̆, N. Ya. Krugljak, Interpolation Functors and Interpolation Spaces, NorthHolland Math. Library 47, North-Holland, Amsterdam 1991.

[22] A. V. Bukhvalov, Spaces with mixed norm, Vestnik Leningrad. Univ. no. 19 Mat. Meh. Astronom. Vyp. 4 (1973), 5-12; English transl.: Vestn. Leningr. Univ. Math. 6 (1979), 303-311.

[23] P. Cembranos, The weak Banach-Saks property on $L^{p}(\mu, E)$, Math. Proc. Cambridge Philos. Soc. 115 (1994), 283-290.

[24] S. Chen, Y. Cui, H. Hudzik, B. Sims, Geometric properties related to fixed point theory in some Banach function lattices, in: Handbook on Metric Fixed Point Theory, Kluwer Acad. Publ., Dordrecht 2001, 339-389.

[25] F. Cobos, L. M. Fernández-Cabrera, M. Mastyło, Abstract limit J-spaces, J. Lond. Math. Soc. (2) 82 (2010), 501-525.

[26] Y. Cui, H. Hudzik, Some geometric properties related to fixed point theory in Cesàro sequence spaces, Collect. Math. 50 (1999), 277-288.

[27] Y. Cui, H. Hudzik, On the Banach-Saks and weak Banach-Saks properties of some Banach sequence spaces, Acta Sci. Math. (Szeged) 65 (1999), 179-187. 
[28] Y. Cui, H. Hudzik, Packing constant for Cesaro sequence spaces, Nonlinear Anal. 47 (2001), 2695-2702.

[29] Y. Cui, H. Hudzik, Y. Li, On the García-Falset coefficient in some Banach sequence spaces, in: Function Spaces (Poznań, 1998), Lecture Notes in Math. 213, Marcel Dekker, New York 2000, 141-148.

[30] Y. Cui, L. Jie, R. Płuciennik, Local uniform nonsquareness in Cesàro sequence spaces, Comment. Math. Prace Mat. 37 (1997), 47-58.

[31] Y. Cui, C. Meng, R. Płuciennik, Banach-Saks property and property $(\beta)$ in Cesàro sequence spaces, Southeast Asian Bull. Math. 24 (2000), 201-210.

[32] J. Diestel, Geometry of Banach Spaces. Selected Topics, Lecture Notes in Math. 485, Springer, Berlin 1975.

[33] J. Diestel, H. Jarchow, A. Tonge, Absolutely Summing Operators, Cambridge Stud. Adv. Math. 43, Cambridge Univ. Press, Cambridge 1995.

[34] S. Dilworth, M. Girardi, J. Hagler, Dual Banach spaces which contain an isometric copy of $L_{1}$, Bull. Polish Acad. Sci. Math. 48 (2000), 1-12.

[35] P. G. Dodds, E. M. Semenov, F. A. Sukochev, The Banach-Saks property in rearrangement invariant spaces, Studia Math. 162 (2004), 263-294.

[36] P. N. Dowling, C. J. Lennard, Every nonreflexive subspace of $L_{1}[0,1]$ fails the fixed point property, Proc. Amer. Math. Soc. 125 (1997), 443-446.

[37] P. N. Dowling, C. J. Lennard, B. Turett, Renormings of $l^{1}$ and $c_{0}$ and fixed point properties, in: Handbook of Metric Fixed Point Theory, Kluwer Acad. Publ., Dordrecht 2001, 269-297.

[38] R. E. Edwards, Functional Analysis. Theory and Applications, Holt, Rinehart and Winston, New York-Toronto-London 1965.

[39] H. W. Ellis, A note on Banach function spaces, Proc. Amer. Math. Soc. 9 (1958), 75-81.

[40] M. Fabian, P. Habala, P. Hájek, V. Montesinos Santalucía, J. Pelant, V. Zizler, Functional Analysis and Infinite-Dimensional Geometry, CMS Books in Math. 8, Springer, New York 2001.

[41] G. H. Hardy, J. E. Littlewood, G. Pólya, Inequalities, Cambridge Univ. Press, Cambridge 1952 .

[42] B. D. Hassard, D. A. Hussein, On Cesàro function spaces, Tamkang J. Math. 4 (1973), $19-25$.

[43] T. Holmstedt, Interpolation of quasi-normed spaces, Math. Scand. 26 (1970), 177-199.

[44] A. A. Jagers, A note on Cesàro sequence spaces, Nieuw Arch. Wisk. (3) 22 (1974), 113-124.

[45] M. I. Kadec, A. Pełczyński, Bases, lacunary sequences and complemented subspaces in the spaces $L_{p}$, Studia Math. 21 (1962), 161-176.

[46] A. Kamińska, D. Kubiak, On the dual of Cesàro function space, Nonlinear Anal. 75 (2012), 2760-2773.

[47] L. V. Kantorovich, G. P. Akilov, Functional Analysis, Nauka, Moscow 1977; English transl.: Pergamon Press, Oxford-Elmsford, NY 1982.

[48] B. S. Kashin, A. A. Saakyan, Orthogonal Series, Nauka, Moscow 1984; English transl.: Transl. Math. Monogr. 75, Amer. Math. Soc., Providence, RI 1989.

[49] R. Kerman, M. Milman, G. Sinnamon, On the Brudny̌̌-Krugljak duality theory of spaces formed by the K-method of interpolation, Rev. Mat. Complut. 20 (2007), 367-389.

[50] P. Kolwicz, K. Leśnik, L. Maligranda, Pointwise products of some Banach function spaces and factorization, J. Funct. Anal. 266 (2014), 616-659.

[51] J. Komlós, A generalization of a problem of Steinhaus, Acta Math. Acad. Sci. Hungar. 18 (1967), 217-229. 
[52] B. I. Korenblyum, S. G. Kreĭn, B. Ya. Levin, On certain nonlinear questions of the theory of singular integrals, Doklady Akad. Nauk SSSR (N.S.) 62 (1948), 17-20 (Russian).

[53] S. G. Kreĭn, Yu. I. Petunin, E. M. Semenov, Interpolation of Linear Operators, Nauka, Moscow, 1978 (Russian); English transl.: Transl. Math. Monogr. 54, Amer. Math. Soc., Providence, 1982.

[54] A. Kufner, L. Maligranda, L.-E. Persson, The Hardy Inequality. About its History and Some Related Results, Vydavatelski Servis, Plzeň 2007.

[55] P. Y. Lee, Cesàro sequence spaces, Math. Chronicle 13 (1984), 29-45.

[56] P. Y. Lee, Cesàro sequence spaces, manuscript, Singapore 1999.

[57] G. M. Leibowitz, A note on the Cesàro sequence spaces, Tamkang J. Math 2 (1971), 151-157.

[58] P.-K. Lin, Köthe-Bochner Function Spaces, Birkhäuser, Boston, 2004.

[59] P.-K. Lin, There is an equivalent norm on $l_{1}$ that has the fixed point property, Nonlinear Anal. 68 (2008), 2303-2308.

[60] J. Lindenstrauss, L. Tzafriri, Classical Banach Spaces I. Sequence Spaces, Ergeb. Math. Grenzgeb. 92, Springer, Berlin, 1977.

[61] J. Lindenstrauss, L. Tzafriri, Classical Banach Spaces II, Ergeb. Math. Grenzgeb. 97, Springer, Berlin, 1979.

[62] Y. Q. Liu, B. E. Wu, P. Y. Lee, Method of Sequence Spaces, Guangdong of Science and Technology Press 1996 (Chinese).

[63] G. Ja. Lozanovskiı̌, Isomorphic Banach lattices, Sibirsk. Mat. Zh. 10 (1969), 93-98; English transl.: Siberian Math. J. 10 (1969), 64-68.

[64] G. Ja. Lozanovskiŭ, Certain Banach lattices, Sibirsk. Mat. Zh. 10 (1969), 584-599; English transl.: Siberian Math. J. 10 (1969), 419-431.

[65] W. A. J. Luxemburg, A. C. Zaanen, Some examples of normed Köthe spaces, Math. Ann. 162 (1965/1966), 337-350.

[66] L. Maligranda, Orlicz Spaces and Interpolation, Sem. Mat. 5, Universidade Estadual de Campinas, Dep. Mat., Campinas, 1989.

[67] L. Maligranda, Type, cotype and convexity properties of quasi-Banach spaces, in: Banach and Function Spaces (Kitakyushu, 2003), Yokohama Publ., Yokohama 2004, 83-120.

[68] L. Maligranda, Calderón-Lozanovskiu construction for mixed norm spaces, Acta Math. Hungar. 103 (2004), 279-302.

[69] L. Maligranda, N. Petrot, S. Suantai, On the James constant and B-convexity of Cesàro and Cesàro-Orlicz sequence spaces, J. Math. Anal. Appl. 326 (2007), 312-331.

[70] M. Mastyło, Banach spaces via sublinear operators, Math. Japon. 36 (1991), 85-92.

[71] M. Mastyło, G. Sinnamon, A Calderón couple of down spaces, J. Funct. Anal. 240 (2006), 192-225.

[72] P. Meyer-Nieberg, Banach Lattices, Universitext, Springer, Berlin 1991.

[73] S. Ya. Novikov, E. M. Semenov, E. V. Tokarev, The structure of subspaces of the space $\Lambda_{p}(\varphi)$, Dokl. Akad. Nauk SSSR 247 (1979), 552-554; English transl.: Soviet Math. Dokl. 20 (1979), 760-761.

[74] S. Ya. Novikov, E. M. Semenov, E. V. Tokarev, On the structure of subspaces of the spaces $\Lambda_{p}(\mu)$, Teor. Funktsiŭ Funktsional. Anal. i Prilozhen. 42 (1984), 91-97; English transl.: Amer. Math. Soc. Transl. Ser. 2 136, Amer. Math. Soc., Providence, RI 1987, $121-127$.

[75] A. Pietsch, History of Banach Spaces and Linear Operators, Birkhäuser, Boston 2007. 
[76] S. A. Rakov, The Banach-Saks exponent of some Banach spaces of sequences, Mat. Zametki 32 (1982), 613-625; English transl.: Math. Notes 32 (1982), 791-797.

[77] V. A. Rodin, E. M. Semyonov, Rademacher series in symmetric spaces, Anal. Math. 1 (1975), 207-222.

[78] E. Sawyer, Boundedness of classical operators on classical Lorentz spaces, Studia Math. 96 (1990), 145-158.

[79] H.-U. Schwarz, Banach Lattices and Operators, Teubner-Texte zur Math. 71, Leipzig 1984.

[80] J. S. Shiue, On the Cesàro sequence spaces, Tamkang J. Math. 1 (1970), 19-25.

[81] J. S. Shiue, A note on Cesàro function space, Tamkang J. Math. 1 (1970), 91-95.

[82] G. Sinnamon, Interpolation of spaces defined by the level function, in: Harmonic Analysis (Sendai, 1990), ICM-90 Satell. Conf. Proc., Springer, Tokyo 1991, 190-193.

[83] G. Sinnamon, The level function in rearrangement invariant spaces, Publ. Mat. 45 (2001), 175-198.

[84] G. Sinnamon, Transferring monotonicity in weighted norm inequalities, Collect. Math. 54 (2003), 181-216.

[85] P. W. Sy, W. Y. Zhang, P. Y. Lee, The dual of Cesàro function spaces, Glas. Mat. Ser. III 22 (1987), 103-112.

[86] W. Szlenk, Sur les suites faiblement convergentes dans l'espace L, Studia Math. 25 (1965), 337-341.

[87] K. Tandori, Über einen speziellen Banachschen Raum, Publ. Math. Debrecen 3 (1954), 263-268.

[88] E. V. Tokarev, The Banach-Saks property in Banach lattices (Russian), Sibirsk. Mat. Zh. 24 (1983), 187-189.

[89] H. Triebel, Interpolation Theory, Function Spaces, Differential Operators, VEB Deutscher Verlag der Wissenschaften, Berlin 1978.

[90] W. Wnuk, $l^{\left(p_{n}\right)}$ spaces with the Dunford-Pettis property, Comment. Math. Prace Mat. 30 (1991), 483-489.

[91] W. Wnuk, Banach Lattices with Order Continuous Norms, PWN, Warszawa, 1999.

[92] A. C. Zaanen, Riesz Spaces II, North-Holland Math. Library 30, North-Holland, Amsterdam 1983. 